Prepared in cooperation with The Nature Conservancy

\title{
Environmental Flow Allocation and Statistics Calculator
}

Open-File Report 2011-1166 



\section{Environmental Flow Allocation and Statistics Calculator}

By Christopher P. Konrad

Prepared in cooperation with The Nature Conservancy

Open-File Report 2011-1166 


\section{U.S. Department of the Interior \\ KEN SALAZAR, Secretary}

\section{U.S. Geological Survey \\ Marcia K. McNutt, Director}

U.S. Geological Survey, Reston, Virginia: 2011

For more information on the USGS-the Federal source for science about the Earth, its natural and living resources, natural hazards, and the environment, visit http://www.usgs.gov or call 1-888-ASK-USGS.

For an overview of USGS information products, including maps, imagery, and publications, visit http://www.usgs.gov/pubprod

To order this and other USGS information products, visit http://store.usgs.gov

Suggested citation:

Konrad, C.P., 2011, Environmental flow allocation and statistics calculator: U.S. Geological Survey Open-File Report 2011-1166, $46 \mathrm{p}$.

Any use of trade, product, or firm names is for descriptive purposes only and does not imply endorsement by the U.S. Government.

Although this report is in the public domain, permission must be secured from the individual copyright owners to reproduce any copyrighted material contained within this report. 


\section{Contents}

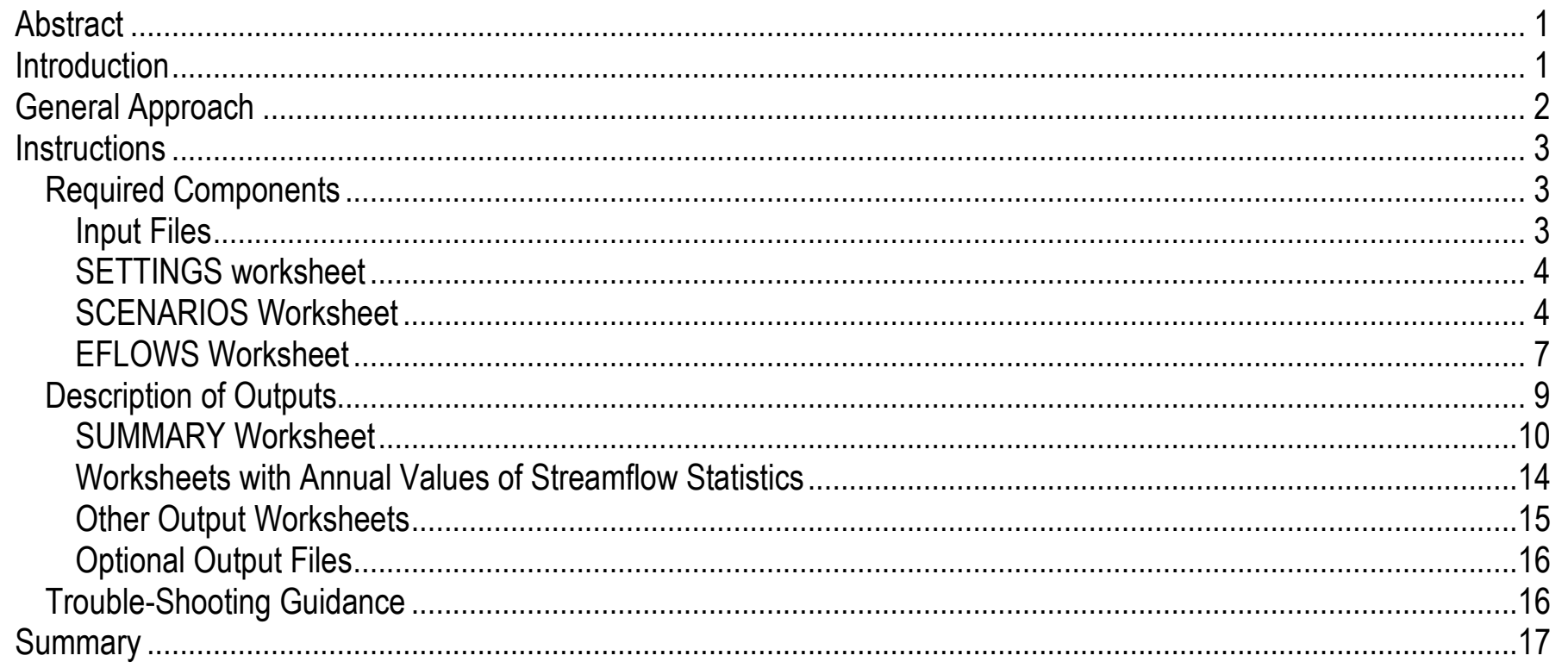

\section{Figures}

Figure 1. Flow chart for using Environmental Flow Allocation and Statistics Calculator (EFASC)......

Figure 2. Flow chart for Environmental Flow Allocation and Statistics Calculator (EFASC) calculations

\section{Conversion Factors}

Inch/Pound to SI

\begin{tabular}{ccc}
\hline Multiply & By & To obtain \\
\hline cubic foot per second $\left(\mathrm{ft}^{3} / \mathrm{s}\right)$ & Flow rate & \\
\hline SI to Inch/Pound & 0.02832 & cubic meter per second $\left(\mathrm{m}^{3} / \mathrm{s}\right)$ \\
\hline Multiply & & \\
\hline & By & To obtain \\
cubic meter per second $\left(\mathrm{m}^{3} / \mathrm{s}\right)$ & Flow rate & \\
\hline
\end{tabular}




\title{
Environmental Flow Allocation and Statistics Calculator
}

\author{
By Christopher P. Konrad
}

\begin{abstract}
The Environmental Flow Allocation and Statistics Calculator (EFASC) is a computer program that calculates hydrologic statistics based on a time series of daily streamflow values. EFASC will calculate statistics for daily streamflow in an input file or will generate synthetic daily flow series from an input file based on rules for allocating and protecting streamflow and then calculate statistics for the synthetic time series. The program reads dates and daily streamflow values from input files. The program writes statistics out to a series of worksheets and text files. Multiple sites can be processed in series as one run. EFASC is written in Microsoft ${ }^{\circledR}$ Visual Basic $^{(}$for Applications and implemented as a macro in Microsoft Office Excel $2007^{\circledR}$. EFASC is intended as a research tool for users familiar with computer programming. The code for EFASC is provided so that it can be modified for specific applications. All users should review how output statistics are calculated and recognize that the algorithms may not comply with conventions used to calculate streamflow statistics published by the U.S. Geological Survey.
\end{abstract}

\section{Introduction}

Streamflow in most rivers and streams varies considerably over time at scales ranging from less than 1 day to decades and longer. The temporal variability and sequencing of streamflow influences biophysical processes ranging from sediment transport to fish migration. Streamflow variability also regulates water availability for human uses. Because of the high degree of temporal variability of streamflow and its broad importance to water availability for river ecosystems and for people living in those systems, various streamflow characteristics must be represented in applications of hydrologic analysis to social and environmental issues. These applications include assessing the availability and reliability of water supplies; modeling of environmental factors influencing biological populations and communities; functional classification of stream types; and identification of ecologically significant impacts of hydrologic alteration resulting from water management, land use, or climate change. No one suite of statistics completely depicts the streamflow characteristics that are important across this range of applications and across landscapes with varied hydrology and ecosystems.

The computer program "Environmental Flow Allocation and Statistics Calculator" (EFASC, available at http://pubs.usgs.gov/of/2011/1166/EFASC_R1.xlsm) was developed to calculate a range of statistics for a daily time series of streamflow and to generate synthetic time-series generated from userspecified rules for allocating and protecting streamflow. The program is intended for research applications and, thus, generates statistics that represent a wide variety of streamflow characteristics. The source code is written in Microsoft ${ }^{\circledR}$ Visual Basic ${ }^{\circledR} 6.5$ for Applications and is executed as a macro in Microsoft Office Excel $2007^{\circledR}$ (MS Excel). The source code is provided in this report (Appendix A) can be copied and executed in MS Excel. Users may also modify or incorporate new algorithms and statistics of interest. EFASC allows batch processing of scenarios that can represent different sites, time 
periods, or protection/allocation rules. EFASC will write the hydrologic time series for any scenario to an ASCII text file permitting further analysis with other hydrologic analysis tools.

EFASC allows a user to specify options for how statistics are calculated. Algorithms for calculating some statistics (e.g., streamflow exceedences) are known to use different conventions than algorithms used to calculate streamflow statistics published by the U.S. Geological Survey (USGS). Because of user options and different conventions, the values of statistics calculated by EFASC are not intended to supersede values published by the USGS including those of the National Streamflow Statistics Program. Deference should be given to streamflow statistics published by the USGS rather than output from EFASC. Any output from EFASC used outside of a research application should be verified by the user to assure the statistical calculation follows the appropriate convention for the specific application of interest.

\section{General Approach}

EFASC calculates statistics from a daily time series. It was developed for daily series of mean streamflow but could be applied to other daily time series (maximum streamflow, temperature, stage). EFASC will calculate statistics either directly from a record of daily streamflow values or from a synthetic daily time series that is derived from a streamflow record plus user-defined rules for allocating and protecting streamflow. Either case is referred to as a "scenario." Each scenario is based on an input file of daily streamflow values.

A user must prepare input data, enter settings, and specify scenarios (fig. 1). EFASC will read the input file and, depending on user specifications, process daily streamflow for a subset period, convert the streamflow to different units, derive a new daily time series to represent streamflow after allocation of water to out-of-stream consumptive uses, and calculate statistics for either the input or derived time series (fig. 2). To compare, for example, an unmodified to modified time series, the user would specify two scenarios - the first scenario with no allocation of water to out-of-stream uses and the second scenario with specified allocation and/or protection rules.

EFASC will generate a synthetic time series based on rules for allocating and protecting streamflow to simulate the outcome of different types of administrative rules for managing water resources. Two types of allocations are allowed: priority allocations made before environmental flow protection rules are applied and additional allocations made after environmental protection rules are applied. Priority allocations can be used to represent senior water rights that allow a user to withdrawal water regardless of junior rights or in-stream flow standards established after the senior right. Additional allocations can be used to represent withdrawals permitted only when in stream flow standards are achieved or a withdrawal subject to a by-pass requirement that protects in-stream flow.

The user can specify unique rules for both types of allocations and the environmental flow protection standards. Neither allocation nor protection rules do not have to be specified, but the user should consult the instructions below to understand the consequences of various combinations of rules. The user can vary allocations and environmental flow standards during a year by defining "bioperiods" on the SCENARIO worksheet using Julian day and, then, specifying allocations and standards for each bioperiod. A bioperiod could be, for example, a typical low-flow period beginning on August 1 (day 213) and ending on September 15 (day 258). 


\section{Instructions}

EFASC must be executed as a macro using MS Excel. Macro functionality must be enabled in MS Excel. The code has both computational algorithms and instructions for computations in MS Excel. The keys "ctrl"+ "e" can be used to run the macro from the MS Excel file.

\section{Components for running the macro}

There are four components for running the EFASC macro: (1) input files with hydrologic timeseries data, (2) settings specified on the worksheet SETTINGS, and (3) scenarios specified on the worksheet SCENARIOS, and (4) any specification of out-of-stream allocations or environmental flow protection standards to generate synthetic time series. Each component is described below.

Input Files

Input files must be formatted as ASCII text with date (year, month, and day) and streamflow (or other attribute such as stage represented by a positive numeric value) on one line for each day. The user may specify the number of header lines to skip before reading data. The four required data fields (year, month, day, and streamflow) should be delimited by commas, spaces, dashes, or semicolons, but the fields may appear in any order. The column number for each of the four fields must be known and specified for each scenario (see SCENARIOS below). The column numbers can be verified by opening up a file in MS Excel and checking to see which columns correspond to each data field. MS Excel will automatically parse text data for files with some extensions (e.g., *.csv). If data from these files are not parsed correctly, the file can be renamed without the extension.

Input data may have gaps, in which case the missing values must be expressed with no line for that day, a blank value for streamflow on the line with date, or "NaN" for the streamflow value. Ice is a common reason for gaps in streamflow records, so daily values of "Ice" are treated as missing values. Other text values will cause an error and should be edited before processing. Zero values will be treated as days with no streamflow and will be used in calculations. Days with missing values are excluded from calculations, which can result in misleading statistics. The user can limit the analysis to years with 365 daily values on the SETTINGS worksheet

The default setting is to treat a dash ("-") as a delimiter, for example, to parse year, month, and day from a date string. If a negative value is used to indicate missing streamflow data, then "-" can be removed from the list of delimiters types used when opening QFILE(l), but dates cannot be formatted with dashes (e.g., 2010-10-01) as the program will not parse out the year, month, and day into separate columns. To remove " - " from the list of delimiters, the command used for opening the data files should be modified so that OtherChar:="-" is instead OtherChar:=False. In this case, the current command,

Workbooks.OpenText Filename:=QFILE(1),

Origin:=437, StartRow:=1, DataType:=xlDelimited, TextQualifier:=xlNone, ConsecutiveDelimiter:=False, Tab:=True, Semicolon:=False, Comma:= True, Space:=True, Other:=True, OtherChar:="-", FieldInfo:=Array( Array $(1,2)$, Array $(2,2))$, TrailingMinusNumbers:=True

would be modified to

Workbooks.OpenText Filename:=QFILE(1), Origin:=437, StartRow:=1, DataType:=x1Delimited, TextQualifier:=xlNone, ConsecutiveDelimiter:=False, Tab:=True, Semicolon:=False, Comma:= True, Space:=True, Other:=True, OtherChar:=False, FieldInfo:=Array( $\operatorname{Array}(1,2)$, Array $(2,2))$, TrailingMinusNumbers:=True 
Among common formats, the EFASC macro will read a "two-column" text file (fig. 1) or files generated by the U.S. Geological Survey National Streamflow Information System (NWIS) using the default format circa 2010, where lines starting with the "\#" character are skipped. Files generated by NWIS have either daily mean streamflow in column 6 or in column 10 when daily maximum and minimum streamflow are also included in the file. The user must specify the column number for daily mean streamflow for each file on the SCENARIOS worksheet. The user should review qualification codes for the each record. Estimated values (qualification code "E") will be processed unless the user manually deletes these values or limits the period of analysis to years without estimated values.

\section{SETTINGS worksheet}

The user must enter four values on the SETTINGS worksheet in cells B2 through B5. The settings are applied to all scenarios that can be modified by a user: (1) a conversion factor to change the units of streamflow so that output has different units than the input, (2) the minimum number of water years (October 1-September 30) in the range of years specified for each scenario required for processing a site, (3) minimum number of days in each water years for that water year to be included in calculations, and (4) the first month of the "low-flow year" used to calculate annual low-flow statistics. The conversion in cell B2 is applied to all output values of streamflow. If the period of analysis is less than the minimum number of years in cell B3, statistics will not be calculated for the scenario. The user can include years with missing data by entering a value less than 365 days in cell B4. Annual low-flow statistics should be calculated for over 12 months beginning with a month unlikely to have low flows. Depending on location, low-flow statistics are commonly calculated based on climate years beginning in April (enter 4 in cell B5), calendar years beginning in January (enter 1 in cell B5), or water years beginning in October (enter 10 in cell B5). Low flow years beginning from June through December are assigned the number of the next calendar year. If the low-flow year begins in a month other than October, there will be less than 12 months in the first and last low flow years.

EFASC is not intended to be used to analyze seasonal or partial records, but records with some missing values can be processed by setting the minimum number of days per year accordingly. Missing data are not equivalent to no-flow values, so seasonal records that excludes periods of no-flow will have different values than the same record that includes no-flow periods for any statistics based on time (e.g., flow duration, medians, means). No high-flow or low-flow periods will be represented during such gaps. The monthly time series of mean streamflow (written to the worksheet MONTHLY_QMEAN) will not include missing months, but it will include months with missing days. In the case of missing days, streamflow for that month will be averaged only over the days with values.

\section{SCENARIOS Worksheet}

The EFASC macro runs a series of user specified scenarios. The user must enter a text string (e.g., a letter) that identifies the scenario, the full name of the file with the streamflow record, a starting and ending year, specifications about the input files, and options for outputs and processing. Each scenario is entered as a separate line on the worksheet SCENARIOS. The macro will process each "scenario" listed on the SCENARIO worksheet starting with line 3 until there is a blank row. Additional scenarios following a blank row will not be processed, but can be used to as a record of previous scenarios. There are 29 columns on the SCENARIOS worksheet for a user to specify the details of each scenario: 


\section{Column A. Scenario}

This is a character code that is appended to the file name to identify output for the scenario. The same characters can be used for multiple scenarios (e.g., "A" could designate scenarios using streamflow records while " $\mathrm{B}$ " could be used to designate scenarios with allocation of water to out-ofstream uses).

Column B. File with streamflow data

Exact name of file including any extension (.txt, .csv, etc.)

Column C. Start year

First year to process, may pre-date streamflow record (e.g., 1900)

Column D. End year

Last year to process, may post-date streamflow record (e.g., 2100)

Column E. NWIS file (0 -no, 1-yes)

Enter 1 to indicate that the file was generated by the National Streamflow Information System using standard format circa 2010, otherwise enter 0.

Column F. Qmean column number (6-NWIS daily mean streamflow, 10-NWIS daily max, min, mean streamflow)

Indicates the field (column) number for daily mean streamflow according to the specified rule for delimiting fields.

Column G. Year column number

Indicates the field (column) number for the calendar year according to the specified rule for delimiting fields.

Column H. Month column number

Indicates the field (column) number for the month according to the specified rule for delimiting fields.

Column I. Day column number

Indicates the field (column) number for the day of the month according to the specified rule for delimiting fields.

Column J. $\quad$ Number of header lines

Indicates the number of header lines preceding streamflow data.

Column K. Type of threshold for high-flow event (1 - streamflow rate, 2 - fraction of time exceeded)

Option for specifying the type of threshold used to define high-flow events. The threshold can be specified in terms of a flow rate using the same units as output (after any conversion applied) or as a fraction of time (0-1) that the threshold streamflow is exceeded (e.g., the streamflow exceeded 0.1 of the time). 
Column L. High-flow threshold (rate or fraction)

Either the flow rate of the threshold or fraction of time the threshold is exceeded depending on option selected in column L.

Column M. Type of threshold for low-flow periods (1 - streamflow rate, 2 - fraction of time exceeded)

Option for specifying the type of threshold used to define low-flow periods. The threshold can be specified in terms of the flow rate using the same units as output (after any conversion applied) or as a fraction of time that the threshold streamflow is exceeded (e.g., the streamflow exceeded 0.9 of the time).

Column N. Low-flow threshold (rate or fraction)

Either the flow rate of the threshold or fraction of time the threshold is exceeded depending on option selected in column $\mathrm{N}$.

Column O. Environmental flow calculations ( 0 - no, 1 - yes)

Option used for scenarios where a synthetic time-series of streamflow will be generated based on specified allocation and protection rules. Enter 0 to calculate statistics based on the daily streamflow record from the input file. Enter 1 to generate a synthetic series using the allocation and protection rules specified on the EFLOWS worksheet.

Column P. Bioperiod 1: the starting day of the year for each bioperiod that can represent months, times of the year associated with distinct life stages for biota, irrigation seasons, or other intra-annual patterns; if January 1 is the start of bioperiod 1 , enter 1

Bioperiods are used to divide a year into continuous periods - each with distinct prior appropriation, environmental flow standards, or additional allocation allowances. Bioperiods are defined by the day of the year that they begin. Specify bioperiod days for a non-leap year. EFASC will adjust the beginning of bioperiods for leap years. A bioperiod will continue to the end of the year or to the day before the next bioperiod begins. For example, if the only bioperiod of interest is from August 1 to September 15, then three bioperiods should be specified even if only one of the bioperiods is used. Bioperiod 1 would begin on day 1, bioperiod 2 would begin on day 213, and bioperiod 3 would begin on day 259. There must be at least one bioperiod beginning on January 1 (day 1).

Column Q. Bioperiod 2: if February is the start of bioperiod 2, enter 32

No entry is required in columns $\mathrm{S}$ through $\mathrm{AC}$ if there is only one bioperiod.

Column R. Bioperiod 3: if March 1 is start of bioperiod 3, enter 60

Column S. Bioperiod 4: if April 1 is start of bioperiod 4, enter 91

Column T. Bioperiod 5: if May 1 is start of bioperiod 5, enter 121

Column U. Bioperiod 6: if June 1 is start of bioperiod 6, enter 152

Column V. Bioperiod 7: if July 1 is start of bioperiod 7, enter 182 
Column W. Bioperiod 8: if August 1 is start of bioperiod 8, enter 213

Column X. Bioperiod 9: if September 1 is start of bioperiod 9, enter 244

Column Y. Bioperiod 10: if October 1 is start of bioperiod 10, enter 274

Column Z. Bioperiod 11: if November 1 is start of bioperiod 11, enter 305

Column AA. Bioperiod 12: if December 1 is start of bioperiod 12, enter 335

Coumn AB. Write daily streamflow to worksheet QDAILY (0-no, 1-yes)

Column AC. Write daily flow duration and monthly streamflow files (0-no, 1-yes)

Option to generating a time-series of monthly statistics and the cumulative distribution streamflow exceeded for each 0.1 percent of the period of analysis ("flow-duration curve").

Column AD. Date to start calculating 100-day statistics (YYYY-MM-DD)

Enter a date using numeric format (YYYY-MM-DD) for the first day of a 100-day period for calculating a subset of statistics. The 100-day statistic can be used, for example, for analysis of streamflow associated with a field sample. This field is optional and can be left blank.

\section{EFLOWS Worksheet}

No specifications are required on this worksheet if the environmental flow calculation option in column O on worksheet "SCENARIOS" for the scenario is"0". Otherwise, the user must specify rules for allocating and protecting streamflow on this sheet.

The synthetic series is calculated in two steps: the specified priority allocation is subtracted from recorded daily streamflow (from the input file), any remaining streamflow is protected up to the specified environmental flow standard at which point any supplementary allocation is subtracted. In this way, priority allocation takes precedent over the environmental flow protection, while the environmental flow protection takes precedence over additional allocation. If additional allocations are not specified, any streamflow remaining after priority allocation will be protected. If additional allocations are specified without an environmental flow standard, they will act like priority allocations (that is, the specified amount of water will be allocated if it is available).

Copy columns A-D of line 2 on EFLOWS workshop down for each scenario. These contain formulas with reference information for the scenarios.

Column A. Scenario

Column B. $\quad$ File with streamflow data

Column C. Start year

Column D. End year 
Fill out columns E-AP for any scenario that has priority allocation, environmental flow protection standards, or additional allocations. These values can be specified in various ways. If streamflow rates are used, verify that the specified values have the same units as streamflow after any conversion noted on the SETTINGS worksheet.

\section{Column E.}

An integer code corresponding to a streamflow statistic that provides a basis for priority allocations:

0 - no priority allocation;

1 - daily streamflow;

2 - mean streamflow;

3 - streamflow exceeded for specified percentile of analysis;

4 - streamflow exceeded for a specified fraction of bioperiod;

5 - mean streamflow for bioperiod;

6 - estimate of 7Q10 based on 10th percentile of the annual (low-flow year) series of 7-day minimum streamflow; or

7 - fixed rate to be entered into each month.

Enter the appropriate integer code.

\section{Column F. Priority allocation in bioperiod 1}

Enter the priority allocation rate in bioperiod 1 using the same units as output (that is, units after any conversion specified on the SETTINGS worksheet). The specified rate will be subtracted from daily streamflow during the bioperiod before any environmental flow protection standard is applied.

Columns G - Q. Priority allocation in bioperiod 2...Priority allocation in bioperiod 12

Enter a rate for each bioperiod specified on the SCENARIOS worksheet.

\section{Column R. ELOW basis}

An integer code corresponding to a streamflow statistic that provides a basis for environmental flow (EFLOW) protection standard:

0 - no EFLOW protection;

1 - daily streamflow;

2 - mean streamflow;

3 - streamflow exceeded for specified percentile of analysis;

4 - streamflow exceeded for a specified fraction of bioperiod;

5 - mean streamflow for bioperiod;

6 - estimate of 7Q10 based on 10th percentile of the annual (low-flow year) series of 7-day minimum streamflow; or

7 - fixed rate to be entered into each month.

Enter the appropriate integer code.

\section{Column S. ENVIRONMENTAL FLOW standard in bioperiod 1}

Fraction of the streamflow statistic specified in previous column or fixed rate for the environmental flow protection standard for each period. Enter a fraction or streamflow rate for bioperiod 1 (specified on the SCENARIOS worksheet). 
Columns T- AD. ENVIRONMENTAL FLOW standard in bioperiod 2....EFLOW standard in bioperiod 12

Enter a fraction or streamflow rate for each bioperiod specified on the SCENARIOS worksheet.

Column Ae. Additional allocation basis

An integer code corresponding to a statistic used for additional allocation after priority allocation and environmental flow protection:

0 - no additional allocation;

1 - daily streamflow;

2 - mean streamflow for the period of analysis;

3 - streamflow exceeded for specified percentile of record;

4 - streamflow exceeded for specified fraction of bioperiod;

5 - mean streamflow for bioperiod;

6 - estimate of 7Q10 based on 10th percentile of the annual (low-flow year) series of 7-day minimum streamflow; or

7 - fixed rate to be entered into each month.

To allocate all streamflow above eflow standard, use code 1 and enter 1 (i.e., 100 percent) for each bioperiod. Enter the appropriate integer code.

Column Af. Additional allocation in bioperiod 1

Fraction of statistic used for or fixed rate of the additional out-of-stream allocation for each month or bioperiod. Enter a fraction or streamflow rate for bioperiod 1.

Columns AG - AQ. Additional allocation in bioperiod 2...Additional allocation in bioperiod 12

Enter a fraction or streamflow rate for each bioperiod specified on the SCENARIOS worksheet.

\section{Description of Outputs}

EFASC generates a series outputs in separate worksheets within the MS Excel file and has options for writing a monthly time series for the period of record of statistics (maximum, mean, median, and minimum streamflow; number of high-flow days; and number of low-flow days) and the cumulative distribution of streamflow to separate files for each scenario. Seven types of outputs are written directly to the EFASC.xlm file:

1. A summary on the worksheet SUMMARY;

2. Annual (water year or low-flow year) values of 18 different statistics (green tabbed worksheets);

3. Summaries of monthly statistics (MONTHQ and MONTH EVENTS);

4. Environmental flow standards and additional allocation by bioperiod (BIOPERIOD);

5. Streamflow statistics for the 100 days prior to the specified date (100-DAY STATS);

6. A time series of monthly mean streamflow (MONTHLY QMEAN); and

7. Daily streamflow (QDAILY).

The scenario label appears in the first column of each output worksheet. The output for any scenario will be written to the same row on each of these sheets unless a worksheet contains output from a previous run, in which case the new output will be appended below the old output. If EFASC is run sequentially without deleting output from previous runs, output in a given row of any of the output sheets will not correspond to the scenario listed in the same row on the SCENARIOS worksheet or to 
the allocation/protection rules listed on the EFLOWS worksheet. In this case, the user will have to keep track of the scenarios and associated allocation/protection rules, for example, by saving the scenarios in order on the SCENARIOS worksheet below a blank row, which will prevent EFASC from re-running the scenarios.

The names of hydrologic statistics can be ambiguous. Based on USGS convention for naming hydrologic statistics, each modifier applies to the next one in order. For example, "annual mean streamflow" is mean streamflow for a given year while "mean annual streamflow" is the mean of annual streamflows. Terminology for monthly statistics is particularly awkward because statistics can be calculated for a specific month (mean streamflow for April 2001) to produce a time series of mean streamflow ("monthly mean streamflow") or for each month of a year (e.g., mean January streamflow) to represent seasonal patterns ("mean monthly streamflow").

\section{SUMMARY Worksheet}

EFASC writes output values directly to columns A through $\mathrm{N}$ of the SUMMARY worksheet. It copies formulas from row 2 of columns $\mathrm{O}-\mathrm{AL}$ to summarize output from other worksheets. Formulas can be entered into row 2 of three additional columns (AM, AN, AO) to calculate additional summary statistics. They will be copied automatically for each scenario. Some of these statistics cannot be calculated for scenarios with one year or no-flow days.

\section{Column A. Scenario}

The name of the data file with the scenario identifier appended.

Column B. Number of years

Number of water years in the period of analysis.

\section{Column C. Mean streamflow}

Mean streamflow for the period of analysis: $\left(\Sigma_{d=1 \text { to } D} Q_{d}\right) / D$, where $D$ is the number of days in the period of analysis.

Column D. Q01

Streamflow equaled or exceeded 1 percent of the period of analysis. Note that the convention for calculating streamflow exceedences is different than percentiles. The streamflow equaled or exceeded 1 percent of the time is calculated by ranking all daily streamflows from highest to lowest and counting down to the streamflow in place $\mathrm{d} / 100$. If $\mathrm{d} / 100$ is not an integer, then the value is interpolated between the integer portion of $\mathrm{d} / 100$ and the next (smaller) value.

Column E. Q10

Streamflow equaled or exceeded 10 percent of the period of analysis.

Column F. Q25

Streamflow equaled or exceeded 25 percent of the period of analysis.

Column G. Q50

Streamflow equaled or exceeded 50 percent of the period of analysis. 
Column H. Q75

Streamflow equaled or exceeded 75 percent of the period of analysis.

Column I.Q90

Streamflow equaled or exceeded 90 percent of the period of analysis.

Column J. Q99

Streamflow equaled or exceeded 99 percent of the period of analysis.

Column K. 50th percentile of absolute value of percent daily change

The median absolute value of percent daily change in streamflow. Percent daily change is calculated for each day $(\mathrm{d}) ;\left(\mathrm{Q}_{\mathrm{day} 1}-\mathrm{Q}_{\mathrm{day} 0}\right) / \mathrm{Q}_{\mathrm{day} 0}$. No-flow days are not included in the calculation. For odd-numbered series, the median is determined by ranking all values for day 1 to day $\mathrm{d}$ in a series from highest to lowest and selecting the value at the $\mathrm{d} / 2+1$ place. For even-numbered series, the value is the midpoint between the integer portion of $\mathrm{d} / 2+1$ and the next (smaller) value.

Column L. Coefficient of variation of daily streamflow

Standard deviation of daily streamflow divided by mean streamflow.

Column M. Coefficient of variation of log-transformed daily streamflow

Coefficient of variation of log-transformed streamflow: $\left(10^{(\operatorname{Var}(\log (\mathrm{Q}))}-1\right)^{0.5}$ where $\operatorname{Var}(\log (\mathrm{Q}))$ is the variance of the series of log-transformed daily values. No-flow days are not included in the calculation.

Column N. Coefficient of variation of log-transformed annual maximum streamflow

Coefficient of variation of log-transformed streamflow: $\left(10^{(\operatorname{Var}(\log (\mathrm{Qmax}))}-1\right)^{0.5}$ where $\operatorname{Var}(\log (Q \max ))$ is the variance of the annual (water year) series of log-transformed maximum daily values. Years when $\mathrm{Qmax}=0$ are not included in the calculation.

Column O. Median annual maximum streamflow (Qmax)

Median annual (water year) maximum daily streamflow.

Column P. Qmax/Q50

Median annual (water year) maximum daily streamflow (Qmax) divided by median streamflow (Q50).

Column Q. Median annual number of high-flow events

Median of the annual (water year) number of periods when streamflow exceeds the high-flow threshold.

Column R. Median annual duration of the longest high-flow event

Median number of days of the annual (water year) longest period of time when streamflow exceeds the high-flow threshold. 
Column S. Number of months with annual probability $>0.5$ of having a high-flow event

Number of months (October, November, December, ..., September) that had flows exceeding the high-flow threshold in more than one-half of the water years of the period of analysis. Values range from 0 to 12 .

\section{Column T. Mode of highest streamflow month}

Most common month of maximum monthly mean streamflow. The time series of monthly mean streamflow is calculated for the period of analysis. The month with the highest monthly mean is determined for each year. A value of 1 indicates that January was most often the month with the highest mean streamflow for the year.

Column U. Median annual minimum streamflow (Qmin)

Median annual (low-flow year) minimum daily streamflow.

Column V. Qmin/Q50

Median annual (low-flow year) minimum daily streamflow (Qmin) divided by median streamflow (Q50).

Column W. Coefficient of variation of annual minimum streamflow

Standard deviation of the annual (water year) series of minimum daily streamflow divided by mean annual minimum daily streamflow.

Column X. Median annual number of low-flow periods

Median of the annual (low-flow year) number of periods when streamflow is less than the lowflow threshold.

Column Y. Median annual duration of the longest low-flow period

Median number of days of the annual (low-flow year) longest period of time when streamflow is less than the low-flow threshold.

Column Z. Number of months with annual probability $>0.5$ of having a low-flow period

Number of months (October, November, December, ..., September) that had flows less than the low-flow threshold in more than one-half of the low-flow years of the period of analysis. Values range from 0 to 12 .

Column AA Mode of lowest streamflow month

Most common month of minimum monthly mean streamflow. The time-series of monthly mean streamflow is calculated for the period of analysis. The month with the lowest monthly mean is determined for each year. A value of 1 indicates that January was most often the month with the lowest mean streamflow for the year.

Column AB. Fraction of years with no-flow days

Fraction of years with days that had no flow. 
Column AC. Mean number of no-flow days in years with no-flow days

The total number of days with no flow averaged over years with no-flow days. Years with streamflow on all days are not included in the calculation. No-flow days are calculated for each lowflow year.

Column AD. Coefficient of variation of annual streamflow

Standard deviation of mean annual (water year) streamflow divided by mean streamflow.

\section{Column AE. Storm-flow recession coefficient (SFR)}

The median annual (water year) value of the $10^{\text {th }}$ percentile of percent daily change for days when streamflow was steady (no change) or receding. The $10^{\text {th }}$ percentile represents a relatively fast recession rate indicative of storm-flow recession because the values are negative.

\section{Column AF. Base-flow recession coefficient (BFR)}

The median annual (water year) value of the median percent daily change for days when streamflow was steady (no change) or receding. The median represents a typical recession rate indicative of base-flow conditions.

Column AG. Maximum monthly streamflow

The maximum of monthly mean streamflow (the maximum of means for January, February, March,..., December).

Column AH. Minimum monthly streamflow

The minimum monthly mean streamflow (the minimum of means for January, February, March,..., December).

Column Al. Maximum coefficient of variation (CV) of monthly streamflow

The coefficient of variation of annual values of mean streamflow for each month (January, February, March,..., December) is calculated and the maximum value is used. The maximum value represents the month with the lowest predictability in streamflow magnitude.

Column AJ. Minimum coefficient of variation (CV) of monthly streamflow

The coefficient of variation of annual values of mean streamflow for each month (January, February, March,..., December) is calculated and the minimum value is used. The minimum value represents the month with the highest predictability in streamflow magnitude.

Column AK. Normalized range of monthly streamflow

Median annual (water year) value of the difference between maximum monthly mean streamflow and minimum monthly mean streamflow divided by annual mean streamflow. If the annual mean streamflow is zero, then the normalized range of monthly streamflow is zero.

Column AL. LOG(Q10/Q90)

Logarithm (base 10) of the streamflow exceeded 10 percent of the time divided by streamflow exceeded 90 percent of the time. If $\mathrm{Q} 90=0$, this field will be blank. 


\section{Column AM. Hydroperiod}

Fraction of period of analysis when streamflow was greater than zero.

\section{Worksheets with Annual Values of Streamflow Statistics}

Annual values of 18 streamflow statistics are written to the green-tabbed worksheets that are labeled by the statistic. The values are calculated for each water year or low-flow year. The corresponding water year is listed on the worksheet "YEAR" in the same column as the annual value of a statistic. The annual values are used to calculate summary statistics (e.g., median annual low streamflow) in the SUMMARY worksheet and can used to evaluate inter-annual variability and trends in streamflow. The value in any given cell (e.g., row 2, column C) corresponds to the water year (or low-flow year) on the worksheet "YEARS" with the same cell address.

YEAR

List of water years in the period of analysis.

QMAX

Maximum daily streamflow for each water year.

\section{QMEAN}

Mean streamflow for each water year.

QMIN

Minimum daily streamflow for each low-flow year.

Q10

Streamflow exceeded 10 percent of the time for each water year.

Q50

Streamflow exceeded 50 percent of the time for each water year.

Q90

Streamflow exceeded 90 percent of the time for each year.

NO_FLOW_DAYS

Number of days with no streamflow for each low-flow year.

HIGH_NUM

The number of high-flow events for each water year.

HIGH_DUR

The duration in days of the longest high-flow event for each water year.

LOW_NUM

The number of low-flow periods for each low-flow year. 
LOW_DUR

The duration in days of the longest low-flow period for each low-flow year.

PDC50

The median absolute value of percent daily change in streamflow for each water year.

CV_LOG_DAILY

The coefficient of variation of log-transformed daily streamflow for each water year.

MONTH MAX

The month with the highest monthly mean streamflow for each water year (1 - January, 12 December).

MONTH MIN

The month with the lowest monthly mean streamflow for each water year (1-January, 12December).

VARMONTH

The difference between maximum monthly mean streamflow and minimum monthly streamflow divided by annual mean streamflow for each water year.

BFR

The base-flow recession coefficient (BFR) for each water year. BFR is median percent daily change for days when streamflow was steady (no change) or receding. The median represents a typical recession rate indicative of base-flow conditions.

SFR

The storm-flow recession coefficient (SFR) for each water year. SFT is the $10^{\text {th }}$ percentile of percent daily change for days when streamflow was steady (no change) or receding. The $10^{\text {th }}$ percentile represents a relatively fast recession rate indicative of storm-flow recession because the values are negative.

\section{Other Output Worksheets}

MONTHQ

MONTHQ has monthly mean streamflow (e.g., mean of annual values of October streamflow), the coefficient of variation of monthly mean streamflow (e.g., the standard deviation of the annual values of October mean streamflow divided by mean October streamflow), and median annual monthly mean streamflow (median of annual values of October mean streamflow).

\section{MONTH_EVENTS}

MONTH_EVENTS has four monthly statistics: (1) median annual duration of the longest highflow event, (2) fraction of years with high streamflows in each month, (3) median annual duration of the longest low-flow period, and (4) fraction of years with low streamflows in each month. 
MONTHLY_QMEAN

A time series of monthly mean streamflow for each month in the period of analysis. BIOPERIODS

The priority allocation, environmental flow standard and additional allocation for each bioperiod.

100_DAY_STATS

Statistics calculated for a 100-day period prior to the date specified for the scenario on the SCENARIOS worksheet. This can be used, for example, to calculate streamflow characteristics prior to collection of biological samples or a site survey.

QDAILY

Daily streamflow values for each scenario are written to this worksheet. For scenarios without appropriations or additional allocations, these values are the same as the input data with any conversion. For other scenarios, appropriations and allocations are subtracted from the daily values according to the rules specified on the EFLOWS worksheet.

\section{Optional Output Files}

In the SCENARIOS worksheet, the user has the option of generating a table of the cumulative distribution of streamflow ("flow duration") and a table of monthly values of minimum, median, mean, and maximum streamflow, frequency of high-flow events, and duration of low streamflows. The cumulative distribution of streamflow is written to the file [input data file name and scenario]_FLOWDUR.CSV and monthly values are written to the file [input data file name and scenario]_MONTH.CSV. Delete these files if you re-run the macro you must overwrite the old version of each file when prompted. Otherwise the program will terminate.

\section{Verification of program}

The program can be verified using the file http://pubs.usgs.gov/of/2011/1166/EFSAC R1_verification.xlsm. and http://pubs.usgs.gov/of/2011/1166/12189500.txt. The verification file has the results of running EFASC using records for water years 1996 to 2000 for USGS station 12189500 (Scenario A). EFASC can be rerun using the same period of analysis (Scenario B). The results for Scenario A and B should be identical.

\section{Trouble-Shooting Guidance}

A user should consult the flow chart (fig. 1) as an overview on how to prevent errors when running EFASC. There are a number of issues that will prevent EFAC from completing a run. Some typical errors are listed below.

Run-time error ' 9 ': Subscript out of range

Close other MS Excel files, debug to check the array that is being referenced.

Run-time error '76': Path not found Close other MS Excel files. 
Run-time error '1004': Method 'OpenText' of object 'Workbooks' failed

Verify that files names are listed correctly in column B of SCENARIOS and are in the same directory as EFASC.

Run-time error '1004': Application-defined or object-defined error Verify that the formatting specified in the scenario is consistent with the input file. Verify that that MS Excel is parsing data from input file into the correct columns.

Run-time error '1004': SaveAs method of Workbook class failed Choose to replace monthly and flow duration files when prompted, delete old versions of these files, or opt to not write output to these files.

Run-time error '13': Type mismatch

Verify that any non-numeric text has been removed from the field with streamflow data in the input file.

Other errors may not cause the program to terminate prematurely, but can produce spurious results or allow the program to terminate without producing output. These include input files that do not have the requisite number of days with data because of gaps in the record and setting the minimum number of years to a value greater than range of years specified in the SCENARIOS worksheet.

\section{Summary}

The Environmental Flow Allocation and Statistics Calculator (EFASC) is a computer program that can be used for calculating streamflow statistics from daily streamflow time series using MS Excel. EFASC will generate a synthetic time series based on user-specified rules for allocating and protecting streamflow to simulate the outcome of different types of administrative rules for managing water resources. Two types of allocations are allowed: (1) priority allocations made before environmental flow protection rules are applied, and (2) additional allocations made after environmental protection rules are applied. A user is required to prepare text files with daily streamflow data, enter settings, and specify scenarios that will be run. The code (appendix A) can be modified to calculate additional statistics and generate output. EFASC is intended as a research tool. Users should verify that statistics generated by EFASC conform to the appropriate conventions for any application. The values generated by EFASC do not supersede the values of streamflow statistics published by the U.S. Geological Survey. 
Prepare daily data file: ASCII text, date and streamflow in separate columns, using tab, space, or hyphen as delimiters between date and streamflow and within date (NWIS format circa 2010 satisfies these criteria); identify the column number that year, month, day, and streamflow will appear in when the file is opened in Excel. These files must be in the same directory as EFASC.

Specify settings on the SETTINGS worksheet: enter any conversion of units, the year basis for low-flow calculations (water, climate, calendar, etc.), and criteria for processing missing data.

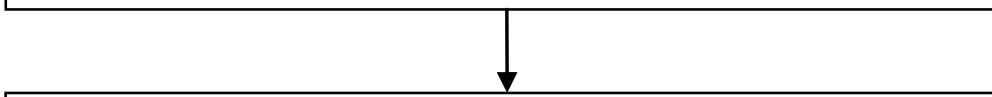

Specify the scenarios on the SCENARIOS worksheet: enter the file name, starting and ending years, input specifications, output options including whether the scenario includes streamflow allocation and/or protection standards; and the starting day of any subyearly periods used in calculations. The macro will process each scenario listed until it reaches a blank line. Scenarios below a blank line will not be processed.

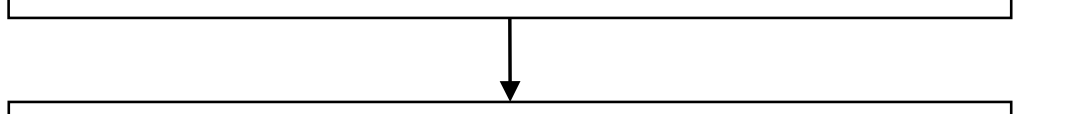

Delete any results that should not be saved on output worksheets beginning with line 3 . Results for each run are appended to any prior results on a worksheet. Do not delete line 2 on SUMMARY worksheet as it contains formulas, which are copied down for each scenario.

\begin{tabular}{|l|}
\hline $\begin{array}{l}\text { Specify priority } \\
\text { allocation, } \\
\text { environmental flow } \\
\text { protection, and } \\
\text { additional allocation } \\
\text { on the EFLOWS } \\
\text { worksheet: } \\
\text { copy cells A2:D2 } \\
\text { down for all scenarios; } \\
\text { specify starting day for } \\
\text { sub-year periods (e.b., } \\
\text { months); specify rules } \\
\text { for allocation and } \\
\text { protection. }\end{array}$ \\
\hline
\end{tabular}

\section{Run macro by selecting the following menu options:} View, Macro, View Macro, EFASC_r1, Run

MS Excel will be opening the input files and manipulating values if the macro is functioning.

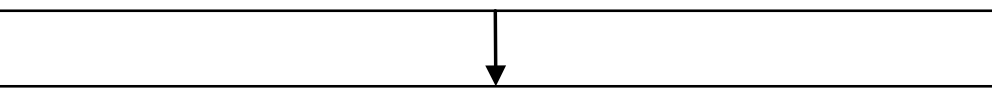

Review and verify output.

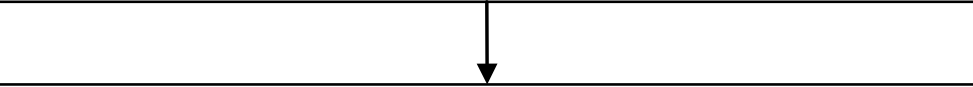

To re-run scenarios, delete results beginning on line 3 of all output sheets. Delete monthly streamflow files and streamflow duration files (if they are specified as output).

To run additional scenarios, enter them in SCENARIOS/EFLOWS worksheets starting on line 3 . The specifications for previous scenarios can be saved on the sheet by copying the them below any new scenarios with a blank line separating new scenarios to be run from those that have alreadv been run.

Figure 1. Flow chart for using Environmental Flow Allocation and Statistics Calculator (EFASC). 


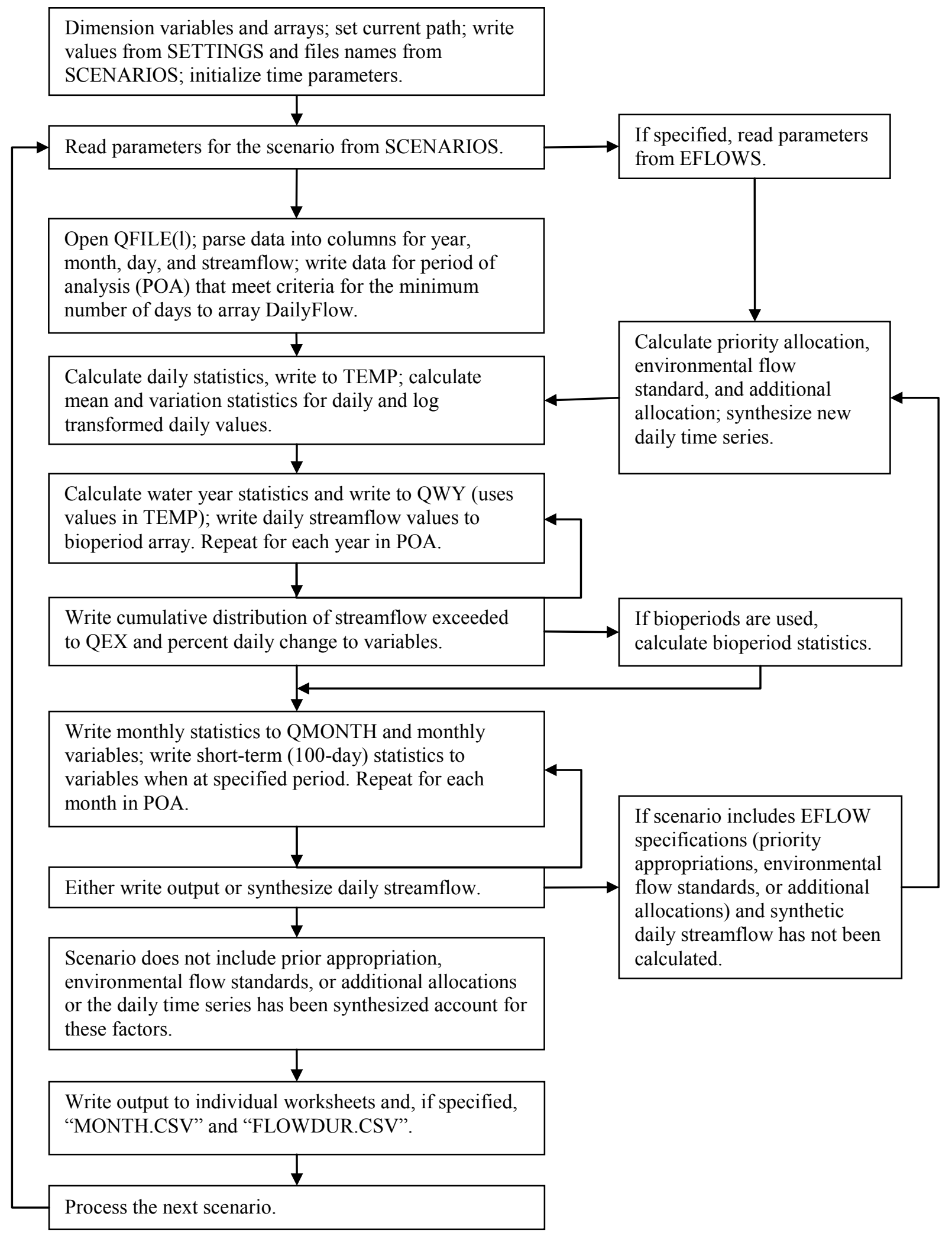

Figure 2. Streamflow chart for Environmental Flow Allocation and Statistics Calculator (EFASC) calculations. 
This page intentionally left blank. 


\section{Appendix A. Visual Basic for Applications Code for Environmental Flow Allocation and Statistics Calculator (EFASC)}

'EFASC calculates streamflow statistics from a time series of daily streamflow. The user can 'specify scenarios that allocate water to out-of-stream uses and protect in-stream flows where 'the rules for allocating and protecting streamflow are based on flow statistics as described 'in US Geological Survey Open-File Report 2011-XXXX.

'The EFASC code was written by Christopher Konrad in Microsoft ${ }^{\circ}$ Visual Basic ${ }^{\circledR} 6.5$ for Applications and 'implemented as a macro in Microsoft Office Excel 2007 ®. This code was last edited on 6 June 2011.

'The program was executed on a Intel ${ }^{\circledR}$ Core $^{\mathrm{TM}} \mathrm{i} 7 \mathrm{CPU}$ running at $2.67 \mathrm{GHz}$ with a 64-bit operating 'system (Microsoft Windows 7 Professional®).

Sub EFASC_R1()

MsgBox ("Environmental Flow Allocation and Statistics Calculator - Release 1 - 6 June 2011")

'Arrays and variables for reading data

Dim FILE NAME(1000) As String, QFILE(1000) As String, DIRECT As String, SCEN(1000) As String

Dim LASTFILE As Integer

'Variables for settings

Dim UNITS As Double, MIN_YEARS As Integer, MIN_DAYS As Integer, LOWFLOW_MONTH As Integer

'Cumulative number of days in the year prior to the first day of each month (leap years adjusted during processing).

Dim JDAYFORMONTH(12) As Integer

JDAYFORMONTH(1) $=0$

JDAYFORMONTH(2) $=31$

JDAYFORMONTH(3) $=59$

JDAYFORMONTH(4) $=90$

$\operatorname{JDAYFORMONTH}(5)=120$

JDAYFORMONTH(6) $=151$

JDAYFORMONTH(7) $=181$

JDAYFORMONTH $(8)=212$

JDAYFORMONTH( $(9)=243$

JDAYFORMONTH $(10)=273$

JDAYFORMONTH $(11)=304$

JDAYFORMONTH $(12)=334$

'Set the current directory, the text files and the workbook with this macro must be in the same directory

ChDir ActiveWorkbook.Path

DIRECT $=$ ActiveWorkbook.Path

'Get settings from sheet "SETTINGS"

Sheets("SETTINGS").Select

Range("b1").Select

UNITS $=$ ActiveCell $(2,1)$

MIN_YEARS $=$ ActiveCell $(3,1)$

MIN_DAYS = ActiveCell $(4,1)$

LOWFLOW_MONTH $=\operatorname{ActiveCell}(5,1)$

'The first column of sheet "SCENARIOS" has a list of the names of the data files. The names are read into a 'character array QFILE(i) 


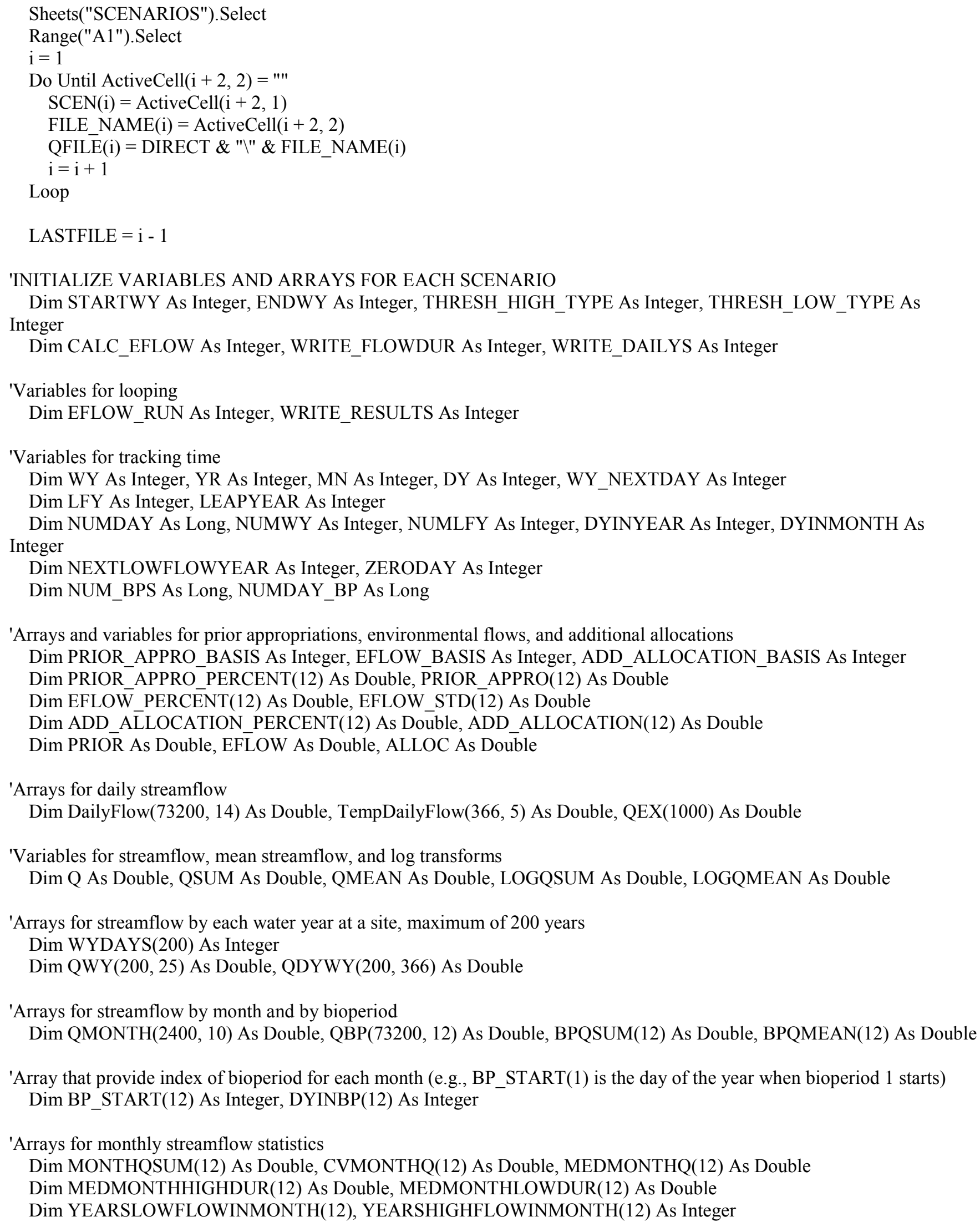


'Variables for daily variation

Dim CVQ As Double, SUMSQDEVQ As Double, CVLOGQ As Double, SUMSQDEVLOGQ As Double

Dim LOGQMAX(200) As Double, MEANLOGQMAX As Double, SSQDEVLOGQMAX As Double, VARLOGQMAX As Double, CVLOGQMAX As Double

'Variables percent daily change

Dim PDC50 As Double

'Variables for indexing location of flows exceeded 10, 50, and 90 percent of the time

Dim TENTH As Integer, MED As Integer, NINETITH As Integer

'Variables for high and low flow events

Dim HIGH_FLOW As Integer, HIGH_YEAR As Integer, DURHIGH As Integer

Dim LOW_FLOW As Integer, LOW_YEAR As Integer, DURLOW As Integer

Dim TH As Double, THRESH_HIGH As Double, TL As Double, THRESH_LOW As Double

'Variable for short-termflow statistics

Dim DYS100PRIOR As Integer, DURHIGH100 As Integer, DURLOW100 As Integer

Dim QMAX100 As Double, QMIN100 As Double, QMEAN100 As Double, PDC100 As Double

Dim SAMPLEDATE As Date, CURRENTDATE As Date

'MAIN LOOP OPENS EACH TEXT FILE WITH STREAMFLOW FOR SCENARIO L

For $\mathrm{L}=1$ To LASTFILE

'READ PARAMETERS FOR EACH SCENARIO

Sheets("SCENARIOS").Select

Range("A1").Select

STARTWY $=$ ActiveCell $(\mathrm{L}+2,3)$

$\mathrm{ENDWY}=\operatorname{ActiveCell}(\mathrm{L}+2,4)$

$\mathrm{QCOL}=$ ActiveCell $(\mathrm{L}+2,6)$

$\mathrm{NWIS}=\operatorname{ActiveCell}(\mathrm{L}+2,5)$

If NWIS $=1$ Then

$\mathrm{YRCOL}=3$

$\mathrm{MNCOL}=4$

$\mathrm{DYCOL}=5$

Else

YRCOL $=$ ActiveCell $(\mathrm{L}+2,7)$

$\mathrm{MNCOL}=$ ActiveCell $(\mathrm{L}+2,8)$

DYCOL $=$ ActiveCell $(\mathrm{L}+2,9)$

NUMHEADERLINES $=$ ActiveCell $(\mathrm{L}+2,10)$

End If

THRESH_HIGH_TYPE $=$ ActiveCell $(\mathrm{L}+2,11)$

$\mathrm{TH}=\operatorname{ActiveCell}(\overline{\mathrm{L}}+2,12)$

THRESH_LOW_TYPE $=\operatorname{ActiveCell}(\mathrm{L}+2,13)$

$\mathrm{TL}=\operatorname{ActiveCell}(\overline{\mathrm{L}}+2,14)$

CALC_EFLOW $=\operatorname{ActiveCell}(\mathrm{L}+2,15)$

For $\mathrm{i}=1$ To 12

BP_START $(\mathrm{i})=\operatorname{ActiveCell}(\mathrm{L}+2, \mathrm{i}+15)$

If BP_START(i) $>0$ Then

NUM_BPS $=\mathrm{i}$

End If

Next

WRITE_DAILYS $=$ ActiveCell $(\mathrm{L}+2,28)$

WRITE_FLOWDUR $=$ ActiveCell $(\mathrm{L}+2,29)$

SAMPLEDATE $=\operatorname{ActiveCell}(\mathrm{L}+2,30)$ 
'READ PARAMETERS FOR PRIOR APPROPRIATION, ENVIRONMENTAL FLOW STANDARDS, AND OTHER ALLOCATIONS

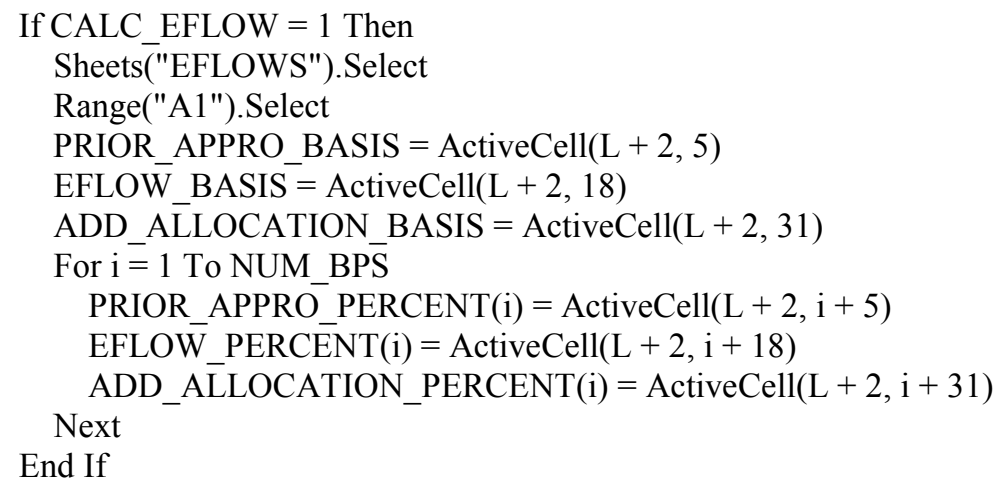

'READ STREAMFLOW DATA FROM THE TEXT FILE IN THE ARRAY QFILE(l) FOR THE INITIAL RUN

'FieldInfo defines data type for each column where Array(column,data type) and data type $=2$ if text

100 If NWIS $=1$ Then

Workbooks.OpenText Filename:=QFILE(L),

Origin:=437, StartRow:=1, DataType:=xlDelimited, TextQualifier:=xlNone, ConsecutiveDelimiter:=False, Tab:=True, Semicolon:=False, Comma:=

True, Space:=True, Other:=True, OtherChar:="-", FieldInfo:=Array(

Array(1,2), Array $(2,2))$, TrailingMinusNumbers:=True

'Bypassess headers

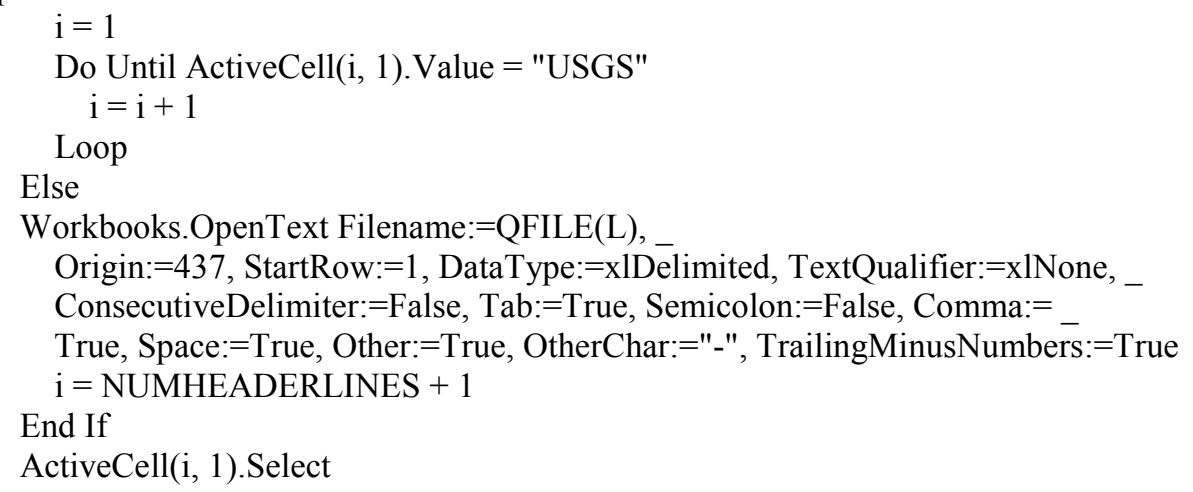

'READ DAILY STREAMFLOW DATA FROM TEXT FILE (year, month, day, Q in specified units) INTO TempDailyFlow 'where $i$ is the row number of the text file and $j$ is the row for the DailyFlow array.

'The loop stops reading at a line without a year. The loop is only executed on streamflow records (EFLOW_RUN=0)

$\mathrm{i}=1$

$\mathrm{j}=0$

Do Until ActiveCell(i, YRCOL) = ""

YR = ActiveCell(i, YRCOL)

$\mathrm{MN}=$ ActiveCell(i, MNCOL)

$\mathrm{DY}=$ ActiveCell(i, DYCOL)

If $\mathrm{MN}>9$ Then

$\mathrm{WY}=\mathrm{YR}+1$

Else

$\mathrm{WY}=\mathrm{YR}$

End If

If ActiveCell $(i+1, \mathrm{MNCOL})>9$ Then

WY_NEXTDAY $=$ ActiveCell $(i+1$, YRCOL $)+1$

Else

WY_NEXTDAY $=$ ActiveCell $(i+1$, YRCOL $)$ 
End If

'The next lines limits processing to the range of water years specified in "SCENARIOS".

If $\mathrm{WY}>=$ STARTWY Then

If WY $<=$ ENDWY Then

If (ActiveCell(i, QCOL) = "Ice") Then

GoTo 200

End If

If $($ ActiveCell(i, QCOL $)=$ "') Then

GoTo 200

End If

If $($ ActiveCell(i, QCOL) = "NaN") Then

GoTo 200

End If

If (ActiveCell(i, QCOL) $<0$ ) Then

GoTo 200

End If

$\mathrm{j}=\mathrm{j}+1$

'TempDailyFlow is used for reading data from the text file one water year at a time.

'TempDailyFlow columns: water year [1], year [2], month [3], day [4], streamflow [5].

'Missing values, $\mathrm{NaN}$, and negative values are skipped.

TempDailyFlow $(\mathrm{j}, 1)=\mathrm{WY}$

TempDailyFlow $(\mathrm{j}, 2)=$ YR

TempDailyFlow $(\mathrm{j}, 3)=\mathrm{MN}$

TempDailyFlow $(\mathrm{j}, 4)=$ DY

TempDailyFlow $(\mathrm{j}, 5)=$ ActiveCell(i, QCOL) $*$ UNITS

'IF A WATER YEAR MEETS THE MINIMUM NUMBER OF DAYS CRITERIA,

'WRITE STREAMFLOW DATA FROM TempDailyFLow TO DailyFlow AND CALCULATE DAILY STATS AT THE END OF EACH WATER YEAR

'NUMDAY is cumulative number of days of record for all years that have minimum number of daily values.

'DailyFlow columns: water year [1], year [2], month [3], day [4], streamflow [5], seven-day low flow [6], 'absolute percent daily change [7], and signed value of percent daily change [8], $\log 10$ of streamflow [9],

'water year number [10], bioperiod [11] assigned to the day, low flow year [12], and number of low flow year [13].

$200 \quad$ If WY $<$ WY NEXTDAY Then

If $\mathrm{j}>=$ MIN_DAYS Then

NUMWY $=$ NUMWY +1

For $\mathrm{k}=1$ To $\mathrm{j}$

NUMDAY $=$ NUMDAY +1

DailyFlow(NUMDAY, 1) = TempDailyFlow $(\mathrm{k}, 1)$

DailyFlow(NUMDAY, 2) $=$ TempDailyFlow $(k, 2)$

DailyFlow(NUMDAY, 3) $=$ TempDailyFlow $(\mathrm{k}, 3)$

DailyFlow(NUMDAY, 4) $=$ TempDailyFlow $(\mathrm{k}, 4)$

DailyFlow(NUMDAY, 5) = TempDailyFlow(k, 5)

DailyFlow(NUMDAY, 10) $=$ NUMWY

If LOWFLOW_MONTH $>=6$ Then

If (DailyFlow(NUMDAY, 3) $>=$ LOWFLOW MONTH) Then

DailyFlow (NUMDAY, 12) $=$ DailyFlow $($ NUMDAY, 2$)+1$

Else

DailyFlow(NUMDAY, 12) = DailyFlow(NUMDAY, 2)

End If

Else

If (DailyFlow(NUMDAY, 3) >= LOWFLOW_MONTH) Then

DailyFlow(NUMDAY, 12) $=$ DailyFlow(NUMDAY, 2)

Else

DailyFlow(NUMDAY, 12) $=$ DailyFlow(NUMDAY, 2) -1 


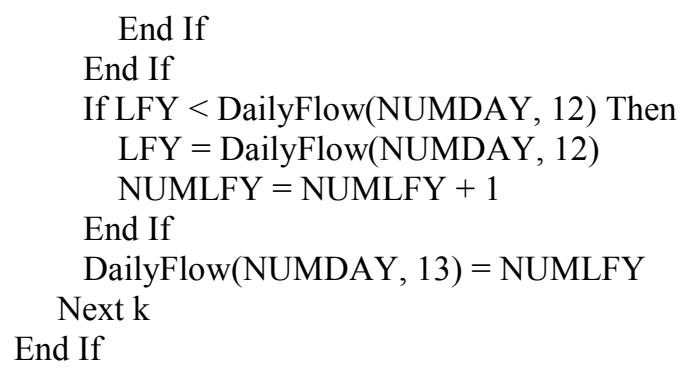

'Reset $\mathrm{j}$ for the next water year

$$
\mathrm{j}=0
$$

'Ends statement WY $<>$ WY_NEXTDAY

End If

'Ends statement IF WY $<$ ENDWY

End If

'Ends statement IF WY > STARTWY

End If

'Advances to the next day (i)

$$
\mathrm{i}=\mathrm{i}+1
$$

$$
\text { Loop }
$$

'The program finished reading data into array DailyFlow and closes the text file.

ActiveWorkbook.Close SaveChanges:=False

'Process sites that met criteria for minimum number of years.

$$
\text { If NUMWY }>=\text { MIN_YEARS Then }
$$

\section{'LOOP TO CALCULATE STREAMFLOW STATISTICS}

'EFLOW_RUN is used to calculate statistics from adjusted streamflow time-series using the eflow standards.

'Initially, EFFLOW_RUN = 0 for each scenario. If there are not allocation or protection rules, statistics are calculated 'from the input data. Otherwise, EFLOW_RUN switches to 1 and the rules are used to generate a synthetic times series, 'which is used to calculate statistics

'This loop is run using data read from the input file (EFLOW_RUN $=0)$ and 're-run for scenarios with EFLOWS on the synthesized daily values after prior appropriations, 'environmental flows, and future allocation (EFLOW_RUN $=1$ ).

$$
\begin{aligned}
& \text { Do While EFLOW_RUN }<2 \\
& \text { ZERODAY }=0 \\
& \text { QSUM }=0 \\
& \text { QMEAN }=0 \\
& \text { SUMSQDEVQ }=0 \\
& \text { CVQ }=0 \\
& \text { LOGQSUM }=0 \\
& \text { LOGQMEAN }=0 \\
& \text { SUMSQDEVLOGQ }=0 \\
& \text { CVLOGQ }=0 \\
& \text { SUMSQDEVLOGQ }=0 \\
& \text { MEANLOGQMAX }=0 \\
& \text { SSQDEVLOGQMAX }=0 \\
& \text { VARLOGQMAX }=0 \\
& \text { CVLOGQMAX }=0 \\
& \text { PDC50 }=0 \\
& \text { TENTH }=0 \\
& \text { MED }=0 \\
& \text { NINETITH }=0 \\
& \text { HIGH_FLOW }=0
\end{aligned}
$$




$$
\begin{aligned}
& \text { HIGH_YEAR }=0 \\
& \text { DURHIGH }=0 \\
& \text { LOW_FLOW }=0 \\
& \text { LOW_YEAR }=0 \\
& \text { DURLOW }=0 \\
& \text { DYS100PRIOR }=0 \\
& \text { FIRST100DAY }=0 \\
& \text { DURHIGH100 }=0 \\
& \text { DURLOW100 }=0 \\
& \text { QMAX100 }=0 \\
& \text { QMIN100 }=0 \\
& \text { QMEAN100 }=0 \\
& \text { PDC100 }=0
\end{aligned}
$$

\section{Erase QWY, QMONTH, QBP, BPQSUM, BPQMEAN, DYINBP, MONTHQSUM, CVMONTHQ, MEDMONTHQ, LOGQMAX \\ Erase MEDMONTHHIGHDUR, MEDMONTHLOWDUR, YEARSLOWFLOWINMONTH, YEARSHIGHFLOWINMONTH}

'Daily flow statistics (mean, 7-day, percent change)

'Calculates QSUM and LOGQSUM

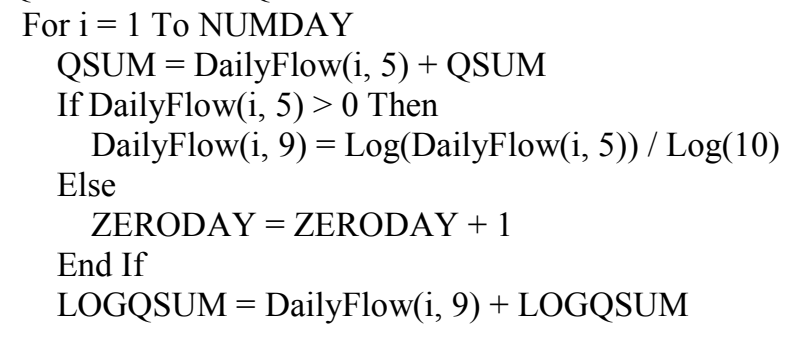

'Write seven day low flow to DailyFlow, column 6

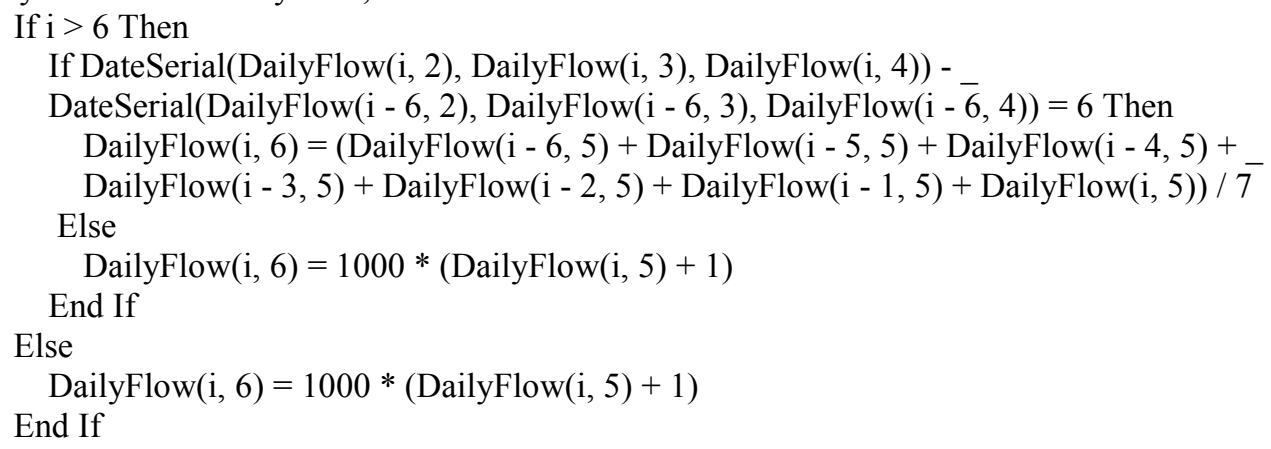

'Write absolute value of daily percent change to DailyFlow, column 7 and signed value daily percent change to DailyFlow, column 8

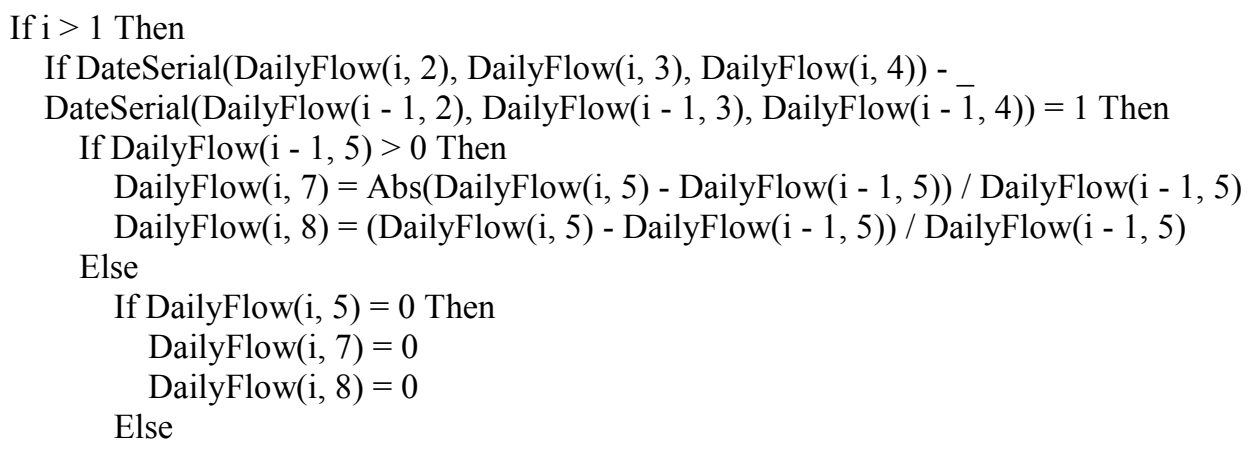




DailyFlow(i, 7)=1
DailyFlow(i, 8)=1
End If
End If
End If
End If
Next i

'WRITE ANNUAL FLOW STATISTICS TO QWY AND BP STATISTICS

'Initialize array QWY that stores water year statistics in columns:

'water year [1], number of days [2], 'Qmean [3], Qmax [4], Q10 [5], Q50 [6], Q90 [7],

'Qmin [8],7-day low flow [9], number of zero flow days [10],

'number of peak events [11], length of longest peak event [12],

'number of low flow events [13], length of longest low flow event [14],

'coefficient of variation of log of daily flows [15],percent daily change [16]

'range of log transformed monthly flows [17], month of high flow [18], month of low flow [19],

'50th percentile of non-zero percent daily change (base flow recession) [20] and

'10th percentile of non-zero percent daily change (storm flow recession) [21].

\section{'CALCULATE STATISTICS FOR EACH WATER YEAR}

' $\mathrm{i}$ indexes each day in the record, $\mathrm{j}$ indexes the water year ordinal number, $\mathrm{k}$ is

'TEMP is used for sorting flow, log flow, and percent daily change.

Sheets("TEMP").Select

Range("A1").Select

For $\mathrm{i}=1$ To NUMDAY

$\mathrm{j}=\operatorname{DailyFlow}(\mathrm{i}, 10)$

If $\operatorname{QWY}(\mathrm{j}, 1)=0$ Then

$\mathrm{k}=0$

End If

$\mathrm{k}=\mathrm{k}+1$

QWY $(\mathrm{j}, 1)=$ DailyFlow $(\mathrm{i}, 1)$

$\mathrm{QWY}(\mathrm{j}, 2)=\mathrm{QWY}(\mathrm{j}, 2)+1$

$\mathrm{QWY}(\mathrm{j}, 3)=\mathrm{QWY}(\mathrm{j}, 3)+$ DailyFlow $(\mathrm{i}, 5)$

If $Q W Y(j, 4)<$ DailyFlow(i, 5) Then

QWY $(\mathrm{j}, 4)=$ DailyFlow $(\mathrm{i}, 5)$

QWY $(\mathrm{j}, 18)=$ DailyFlow $(\mathrm{i}, 3)$

\section{End If}

'Annual minimum, 7-day low flow, and number of no-flow days for the low-flow year

NUMLFY = DailyFlow $(i, 13)$

QWY(NUMLFY, 8) $=$ DailyFlow (i, 5)

QWY(NUMLFY, 9) = DailyFlow(i, 6)

QWY(NUMLFY, 10) $=0$

QWY(NUMLFY, 19) $=$ DailyFlow $(i, 3)$

If QWY(NUMLFY, 8) > DailyFlow(i, 5) Then

QWY(NUMLFY, 8) $=$ DailyFlow $(\mathrm{i}, 5)$

QWY(NUMLFY, 19) = DailyFlow (i, 3)

End If

If QWY(NUMLFY, 9) > DailyFlow(i, 6) Then

QWY(NUMLFY, 9) = DailyFlow(i, 6)

End If

If DailyFlow $(i, 5)=0$ Then

End If

QWY $($ NUMLFY, 10) $=$ QWY $($ NUMLFY, 10) +1 
'WRITE DATA TO BP ARRAYS

'Calculate julian day to evaluate bioperiod - neither are adjusted for leap years

DYINYEAR = JDAYFORMONTH(DailyFlow $(\mathrm{i}, 3))+\operatorname{DailyFlow}(\mathrm{i}, 4)$

'Determine the bioperiod (b) for the current day (DYINYEAR), account for Feb 29

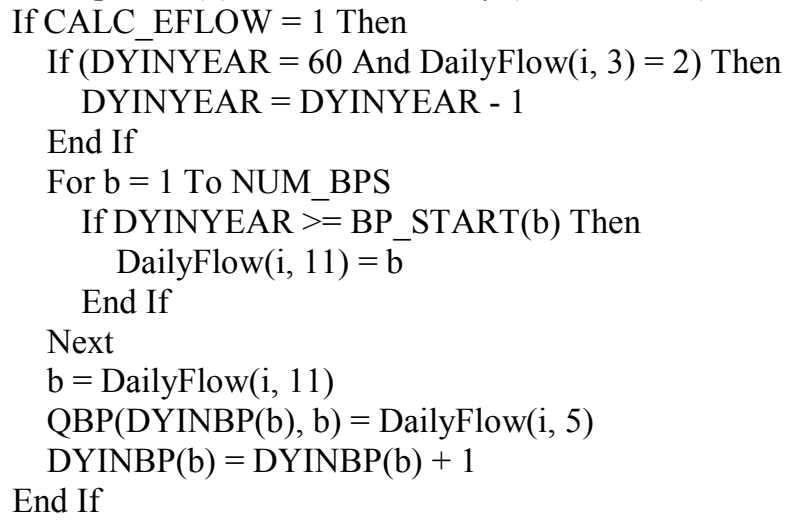

'WRITE FLOW AND PERCENT DAILY CHANGE DATA FROM DailyFlow ARRAY TO "TEMP" SHEET FOR EACH WATER YEAR

ActiveCell $(\mathrm{k}, 1)=\operatorname{DailyFlow}(\mathrm{i}, 5)$

ActiveCell $(\mathrm{k}, 2)=\operatorname{DailyFlow}(\mathrm{i}, 9)$

ActiveCell $(\mathrm{k}, 3)=\operatorname{DailyFlow}(\mathrm{i}, 7)$

ActiveCell $(\mathrm{k}, 4)=\operatorname{DailyFlow}(\mathrm{i}, 8)$

'CALCULATE STATISTICS AT THE END OF THE WATER YEAR

'Mean annual flow and WY flow duration(Q10, Q50, Q90) statistics

If DailyFlow(i $+1,1)<>$ QWY $(j, 1)$ Then

QWY $(\mathrm{j}, 3)=\mathrm{QWY}(\mathrm{j}, 3) / \mathrm{QWY}(\mathrm{j}, 2)$

Range(ActiveCell(1, 1), ActiveCell(QWY(j, 2), 4)).Select

Selection.Sort Key1:=ActiveCell, Order1:=xlDescending,

Header:=xlNo, OrderCustom:=1, MatchCase:=False,

Orientation:=xlTopToBottom, DataOption $1:=x 1$ SortNormal

ActiveCell $(1,1)$. Select

$\mathrm{TENTH}=\operatorname{Int}(\mathrm{QWY}(\mathrm{j}, 2) * 0.1)$

$\mathrm{MED}=\operatorname{Int}(\mathrm{QWY}(\mathrm{j}, 2) * 0.5)$

NINETITH $=\operatorname{Int}(\mathrm{QWY}(\mathrm{j}, 2) * 0.9)$

0.1 - TENTH)

QWY $(\mathrm{j}, 5)=$ ActiveCell $($ TENTH, 1$)-($ ActiveCell $($ TENTH, 1) - ActiveCell $($ TENTH + 1, 1)) * $(\mathrm{QWY}(\mathrm{j}, 2)$ *

MED)

QWY $(\mathrm{j}, 6)=\operatorname{ActiveCell}(\mathrm{MED}, 1)-(\operatorname{ActiveCell}(\mathrm{MED}, 1)-\operatorname{ActiveCell}(\mathrm{MED}+1,1)) *(\mathrm{QWY}(\mathrm{j}, 2) * 0.5-$

QWY $(\mathrm{j}, 7)=$ ActiveCell(NINETITH, 1) - (ActiveCell(NINETITH, 1) - ActiveCell(NINETITH + 1, 1)) * $(\mathrm{QWY}(\mathrm{j}, 2) * 0.9-\mathrm{NINETITH})$

If $(\mathrm{QWY}(\mathrm{j}, 2)-\mathrm{QWY}(\mathrm{j}, 10))>1$ Then

'Annual variance of $\log$ transformed flows used to calculate annual coefficient of variation

QWY $(j, 15)=$ WorksheetFunction.Var(Range $(\operatorname{ActiveCell}(1,2), \operatorname{ActiveCell}(Q W Y(j, 2)-Q W Y(j, 10), 2)))$

'Annual median absolute percent daily change in streamflow

QWY $(\mathrm{j}, 16)=$ WorksheetFunction.Median $(\operatorname{Range}(\operatorname{ActiveCell}(1,3), \operatorname{ActiveCell}(\mathrm{QWY}(\mathrm{j}, 2)-\mathrm{QWY}(\mathrm{j}, 10)$,

3)))

End If

'Annual median of non-positive percent daily change (base flow recession)

If QWY $(j, 2)>Q W Y(j, 10)$ Then 
Range(ActiveCell(1, 4), ActiveCell(QWY(j, 2) - QWY(j, 10), 4)).Select

If QWY $(j, 16)>0$ Then

Selection.Sort Key1:=ActiveCell, Order1:=xlAscending,

Header:=xlNo, OrderCustom:=1, MatchCase:=False,

Orientation:=xlTopToBottom, DataOption1: $=x 1$ SortNormal

$\mathrm{k}=1$

Do Until ActiveCell $(\mathrm{k}, 1)>0$

$\mathrm{k}=\mathrm{k}+1$

Loop

MED $=\operatorname{Int}(\mathrm{k} * 0.5)$

TENTH $=\operatorname{Int}(\mathrm{k} * 0.1)$

$\mathrm{QWY}(\mathrm{j}, 20)=\operatorname{ActiveCell}(\mathrm{MED}, 1)-($ ActiveCell $(\mathrm{MED}, 1)-\operatorname{ActiveCell}(\mathrm{MED}+1,1)) *(\mathrm{k} * 0.5-\mathrm{MED})$

If TENTH $>0$ Then

QWY $(\mathrm{j}, 21)=$ ActiveCell $($ TENTH, 1$)-($ ActiveCell $($ TENTH, 1$)-\operatorname{ActiveCell}($ TENTH $+1,1)) *(\mathrm{k} *$

0.1 - TENTH)

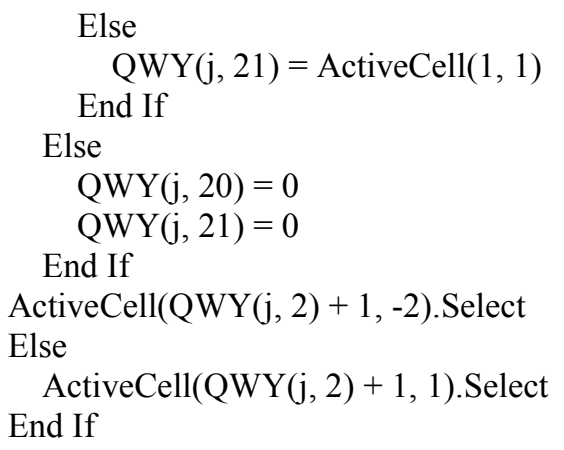

'Advance the active cell in TEMP to the first line of the next water year

End If

Next $\mathrm{i}$

'CALCULATE MEAN AND VARIABILITY STATISTICS FOR PERIOD OF ANALYSIS

QMEAN $=$ QSUM $/$ NUMDAY

LOGQMEAN $=$ LOGQSUM $/($ NUMDAY - ZERODAY $)$

For $\mathrm{i}=1$ To NUMDAY

SUMSQDEVQ $=($ DailyFlow $(i, 5)-$ QMEAN $) \wedge 2+$ SUMSQDEVQ

SUMSQDEVLOGQ $=\left(\right.$ DailyFlow $(\mathrm{i}, 9)-$ LOGQMEAN $^{\wedge} \wedge 2+\mathrm{SUMSQDEVLOGQ}^{\circ}$

Next i

'Coefficient of variation of daily flows

$\mathrm{CVQ}=\left((\mathrm{SUMSQDEVQ} /(\mathrm{NUMDAY}-1))^{\wedge} 0.5\right) / \mathrm{QMEAN}$

'Coefficient of variation of log daily flows transformed back into dimensional space

If SUMSQDEVLOGQ / (NUMDAY - ZERODAY - 1) $<100$ Then End If

$\mathrm{CVLOGQ}=\left(10^{\wedge}(\mathrm{SUMSQDEVLOGQ} /(\mathrm{NUMDAY}-\mathrm{ZERODAY}-1))-1\right) \wedge 0.5$

'Initialize array QEX that stores flow duration values where the index (i) is 10 times duration that the given flow is exceeded '(e.g., QEX(1) is the flow exceeded 0.1 percent of the time, QEX(100) is the flow exceeded 10 percent of the time).

'QEX has flow exceeded from 0.1 to 100 percent of the time in increments of 0.1 percent.

For $\mathrm{i}=1$ To 1000

$\mathrm{QEX}(\mathrm{i})=0$

Next i

'Sorts streamflow data in "TEMP" in descending order, fills an array (QEX) with streamflow equaled or 'exceeded 0.1 to 100 percent of the time in increments of 0.1 time for record of complete water years.

'If there is not an exact number of days corresponding to a given duration (i/1000), an average of flows

'for days $\mathrm{j}$ and $\mathrm{j}+1$ is weighted by the difference between $\mathrm{j} / \mathrm{NUMDAY}$ and $\mathrm{i} / 1000$.

'The first value in the array, $\operatorname{QEX}(0,1)$, is the maximum flow.

Range("A1:d1").Select 


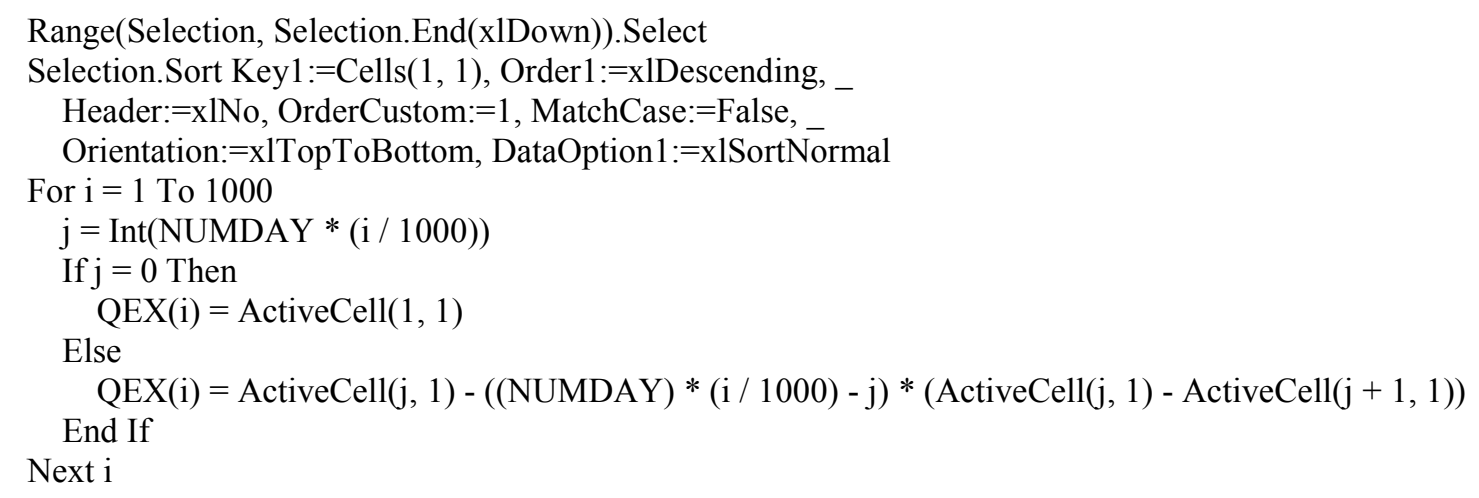

'Thresholds for high flow and low flow events

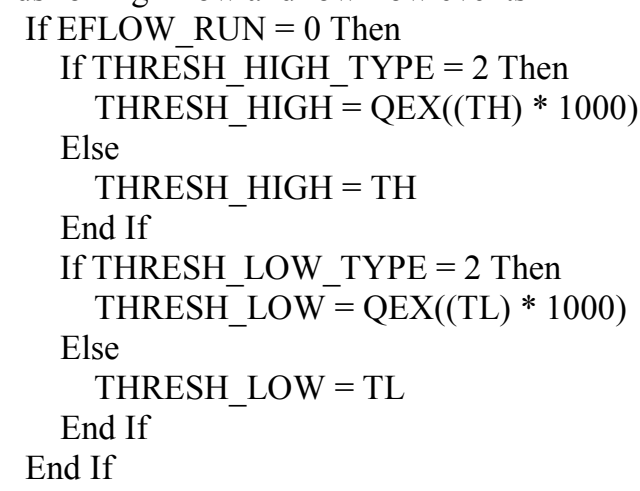

'Calculate median absolute percent daily change for days with streamflow

Range("C1").Select

Range(ActiveCell( $(1,1)$, ActiveCell(NUMDAY - ZERODAY, 1)).Select

Selection.Sort Key1:=ActiveCell, Order1:=xlDescending,

Header:=xlNo, OrderCustom:=1, MatchCase:=False,

Orientation:=xlTopToBottom, DataOption1:=xlSortNormal

$\mathrm{j}=\operatorname{Int}(\mathrm{NUMDAY}+1) / 2$

PDC50 = ActiveCell( $\mathrm{j}, 1)-($ ActiveCell $(\mathrm{j}, 1)-\operatorname{ActiveCell}(\mathrm{j}+1,1)) *((\operatorname{NUMDAY}+1) / 2-\mathrm{j})$

Range("A1:D1").Select

Range(Selection, Selection.End(xlDown)).ClearContents

'Estimated 10-year, 7-day flow flow

Range("A1").Select

For $\mathrm{i}=1$ To NUMLFY

ActiveCell $(\mathrm{i}, 1)=\mathrm{QWY}(\mathrm{i}, 9)$

Next i

EST7Q10 = Application.WorksheetFunction.Percentile(Range(ActiveCell(1, 1), ActiveCell(i, 1)), 0.1)

Range(ActiveCell( $(1,1)$, ActiveCell(i, 1)).ClearContents

'Bioperiod calculations if environmental flow standard or additional allocation is based on exceedence percentile in period, 'otherwise, bioperiod calculations are done after other flow statistics

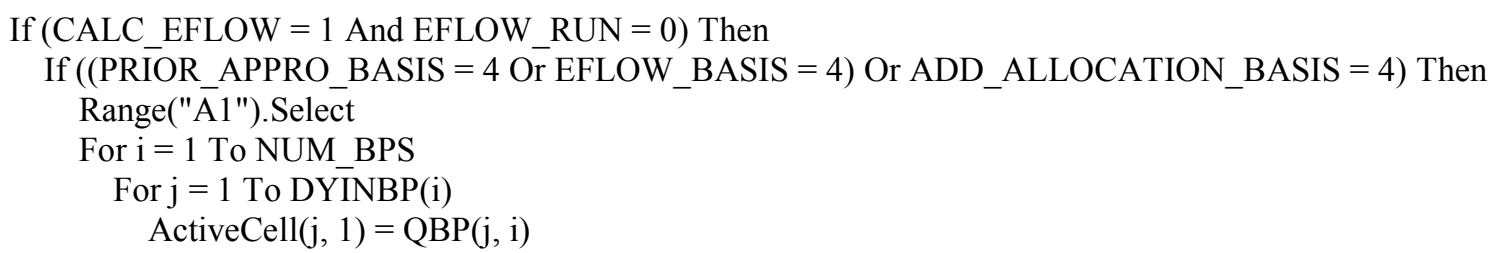




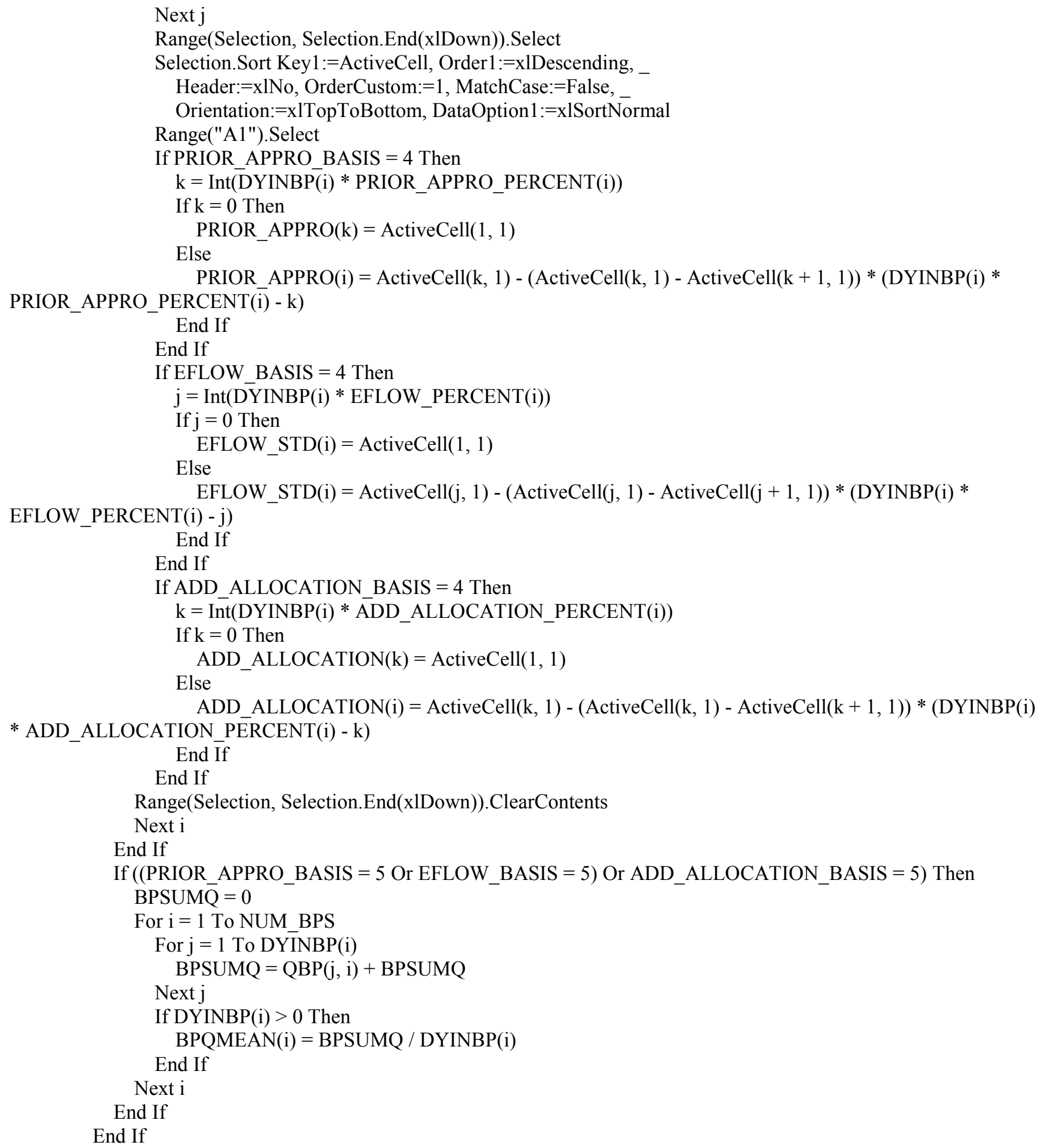




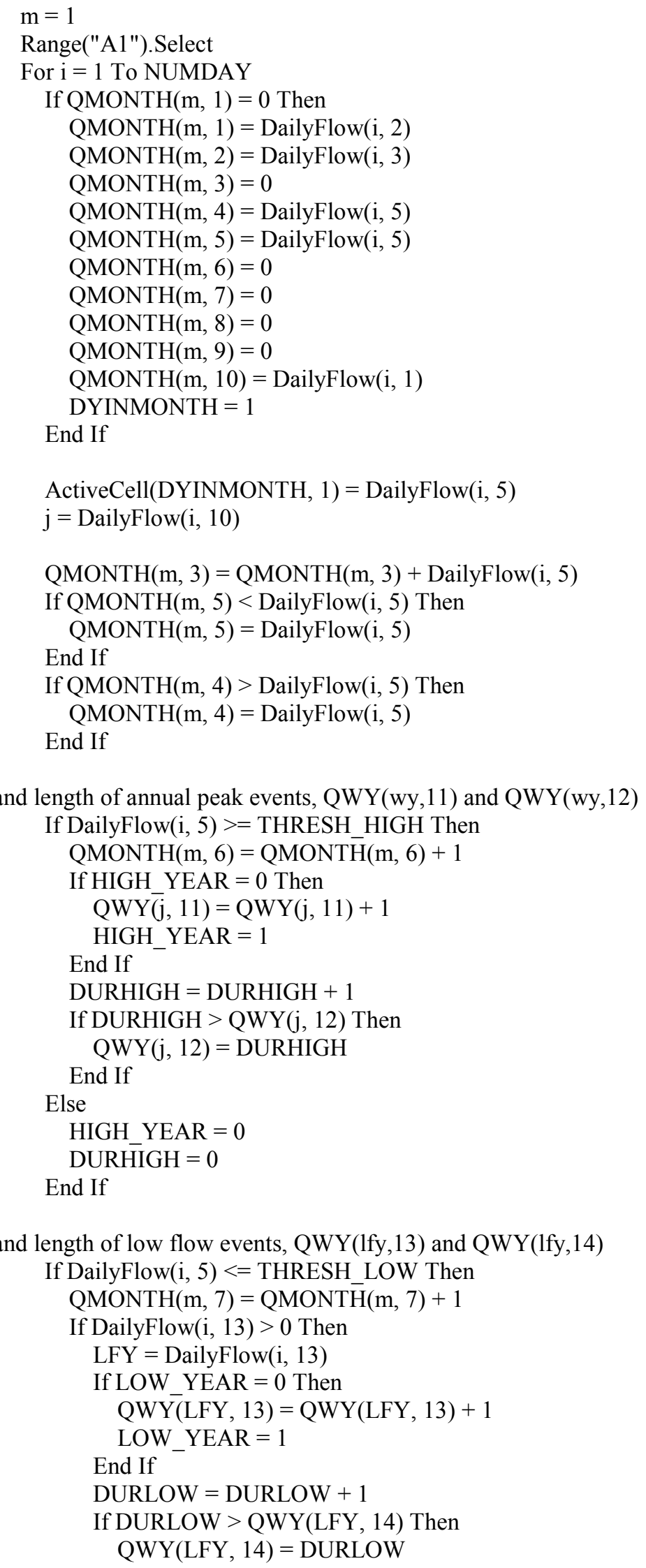




End If
End If
Else
LOW_MONTH $=0$
LOW_YEAR $=0$
DURLOW $=0$
End If

'If the next line of DailyFlow is from the next month, then Qmean and Qmedian for the month are calculated and 'the month index m move forward.

If DailyFlow(i, 3) $<$ DailyFlow(i $+1,3)$ Then

$\operatorname{QMONTH}(\mathrm{m}, 3)=\operatorname{QMONTH}(\mathrm{m}, 3) /$ DYINMONTH

$\operatorname{QMONTH}(\mathrm{m}, 8)=$ Application.WorksheetFunction.Median(Range(Selection, Selection.End(xlDown)))

Range(Selection, Selection.End(xlDown)).ClearContents

$\mathrm{m}=\mathrm{m}+1$

Else

End If

DYINMONTH $=$ DYINMONTH +1

'Statististics for flows 100 days prior to sampling

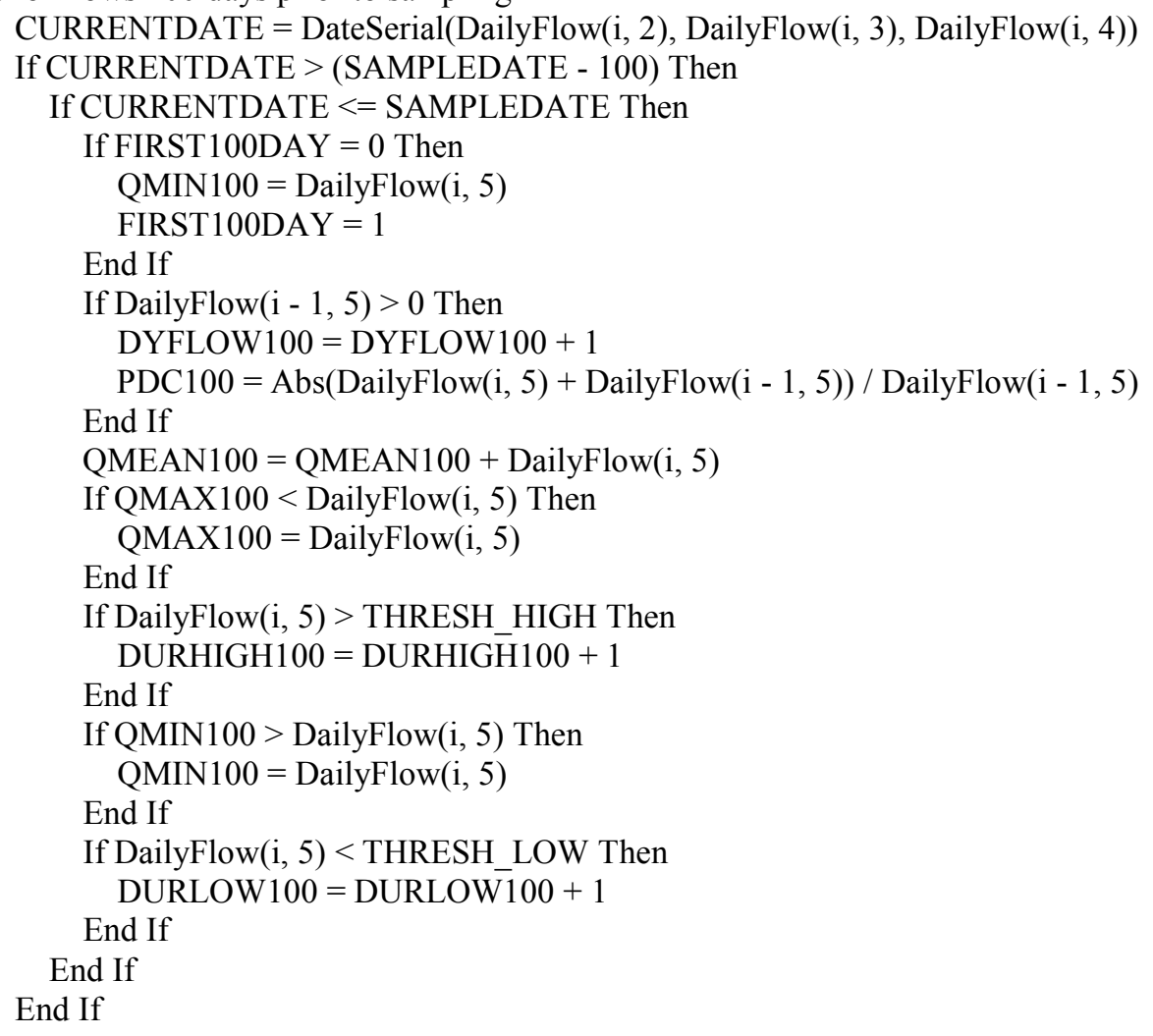

'Reset values for new water year

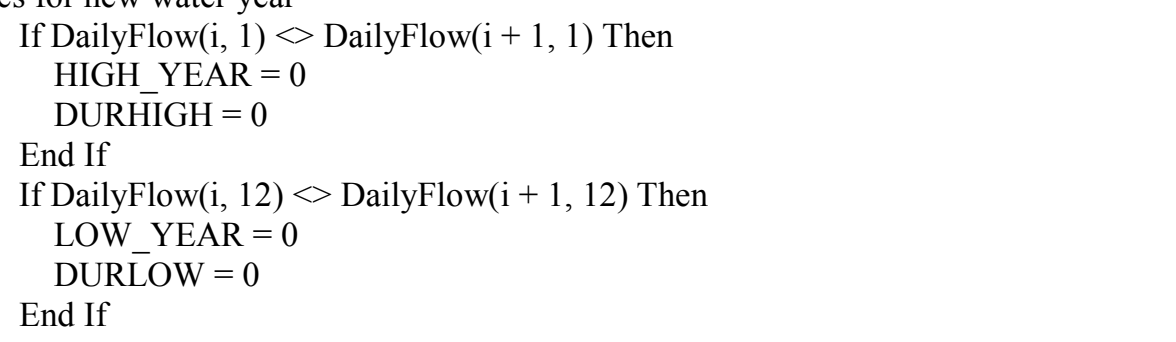


Next i

$\mathrm{m}=\mathrm{m}-1$

'Median monthly mean

$\mathrm{k}=1$

Range("A1").Select

For $\mathrm{i}=1$ To $\mathrm{m}$

$\mathrm{j}=\operatorname{Int}(\mathrm{QMONTH}(\mathrm{i}, 2))$

$\operatorname{MONTHQSUM}(\mathrm{j})=$ QMONTH $(\mathrm{i}, 3)+\operatorname{MONTHQSUM}(\mathrm{j})$

$\mathrm{k}=\operatorname{Int}((\mathrm{i}-1) / 12+1)$

$\operatorname{ActiveCell}(\mathrm{k}, \mathrm{j})=\mathrm{QMONTH}(\mathrm{i}, 3)$

Next i

For $\mathrm{i}=1$ To 12

Range(ActiveCell( $(1, \mathrm{i})$, ActiveCell(k, i)).Name = "MonthRange"

If Application.WorksheetFunction.Count(Range("MonthRange")) $>0$ Then

MEDMONTHQ(i) = Application.WorksheetFunction.Median(Range("MonthRange"))

If Application. WorksheetFunction.Average(Range("MonthRange")) $>0$ Then

If $\mathrm{k}>1$ Then

CVMONTHQ(i) = Application.WorksheetFunction.StDev(Range("MonthRange")) /

Application.WorksheetFunction.Average(Range("MonthRange"))

End If

End If

End If

Range("A1").Select

Next i

'Annual variation of monthly streamflow

For $\mathrm{i}=1$ To NUMWY

Range(ActiveCell(i, 1), ActiveCell(i, 12)).Name = "MonthRange"

If QWY $(i, 3)>0$ Then

If Application.WorksheetFunction.Min(Range("MonthRange")) $>0$ Then

QWY $(\mathrm{i}, 17)=($ Application.WorksheetFunction.Max $($ Range("MonthRange") $)$ -

(Application.WorksheetFunction.Min(Range("MonthRange")))) / QWY(i, 3)

End If

Else

QWY $(i, 17)=0$

End If

Next i

Range(ActiveCell(1, 1), ActiveCell(NUMWY, 12)).ClearContents

'Monthly statistics of high flow events and low flow events

' $\mathrm{i}$ is the month for the period of analysis, $\mathrm{j}$ is the month number (1 to 12), and $\mathrm{k}$ is year

For $\mathrm{i}=1$ To $\mathrm{m}$

$\mathrm{j}=\operatorname{Int}(\mathrm{QMONTH}(\mathrm{i}, 2))$

$\mathrm{k}=\operatorname{Int}((\mathrm{i}-1) / 12+1)$

ActiveCell $(\mathrm{k}, \mathrm{j})=\mathrm{QMONTH}(\mathrm{i}, 6)$

If QMONTH $(\mathrm{i}, 6)>0$ Then

YEARSHIGHFLOWINMONTH(j) = YEARSHIGHFLOWINMONTH(j) + 1 End If

Next i

For $\mathrm{i}=1$ To 12

Range(ActiveCell( $(1, \mathrm{i})$, ActiveCell(k, i)).Name = "MonthRange"

If Application.WorksheetFunction.Count(Range("MonthRange")) $>0$ Then

MEDMONTHHIGHDUR(i) = Application.WorksheetFunction.Median(Range("MonthRange")) 
ActiveCell( $(\mathrm{A}, \mathrm{i}+1)$. Value $=\mathrm{QWY}(\mathrm{i}, 3)$

Next i

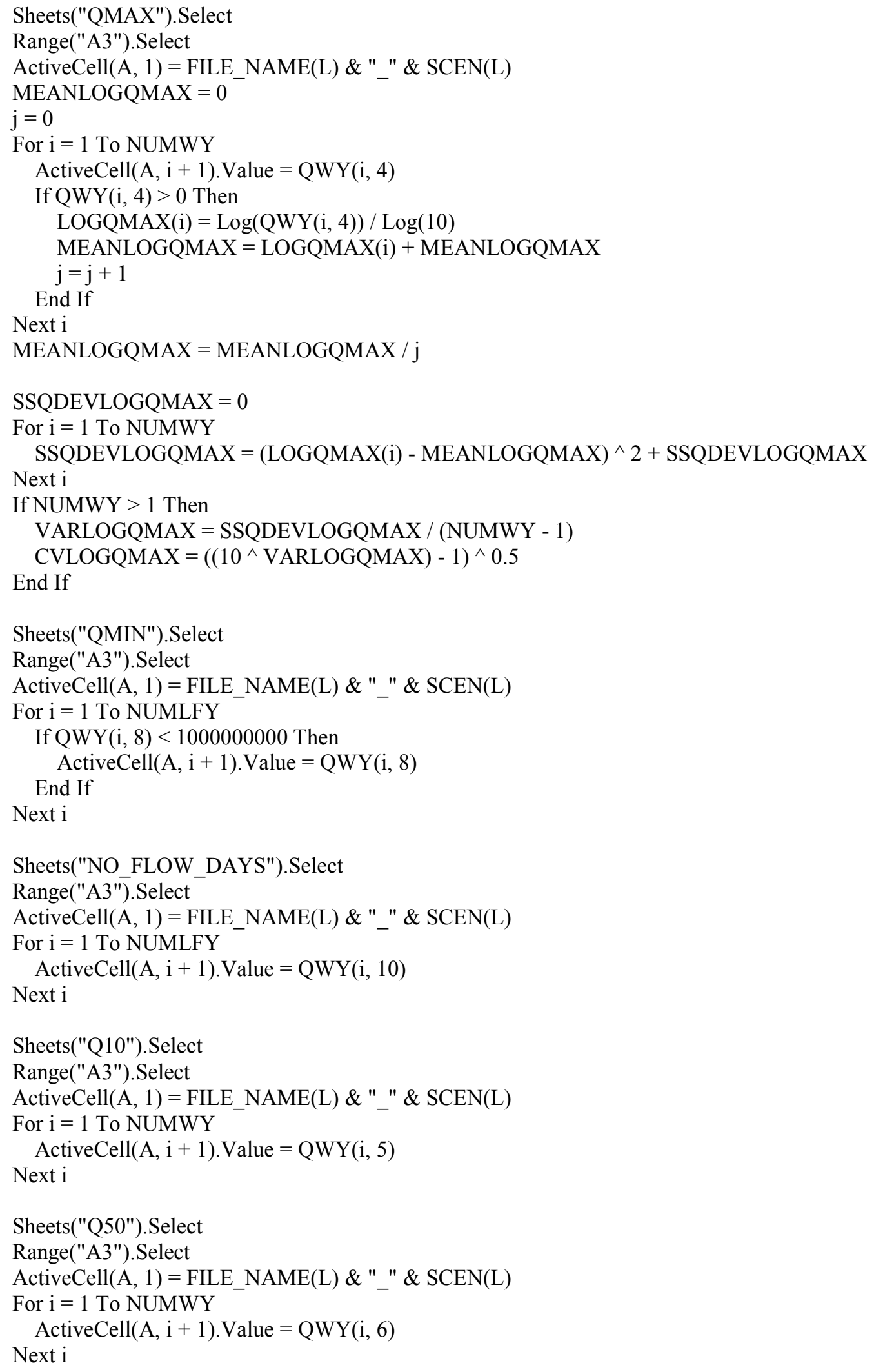




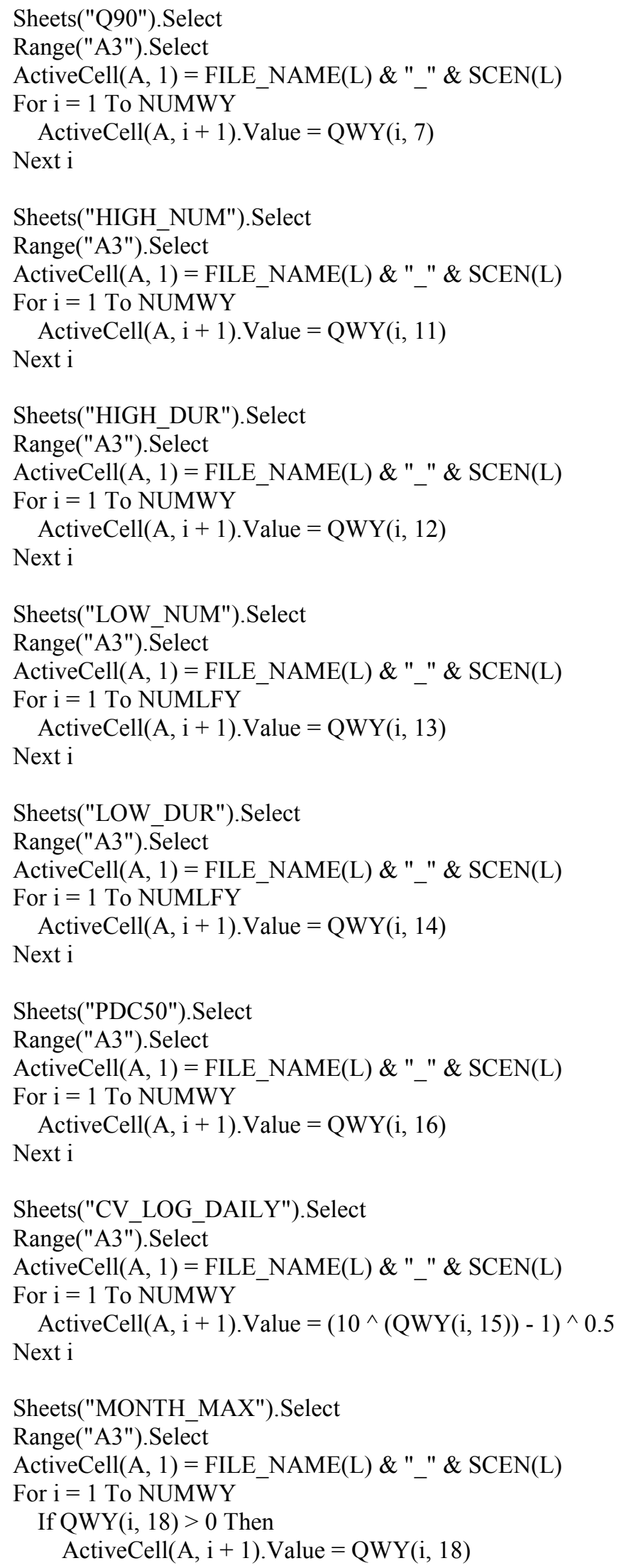




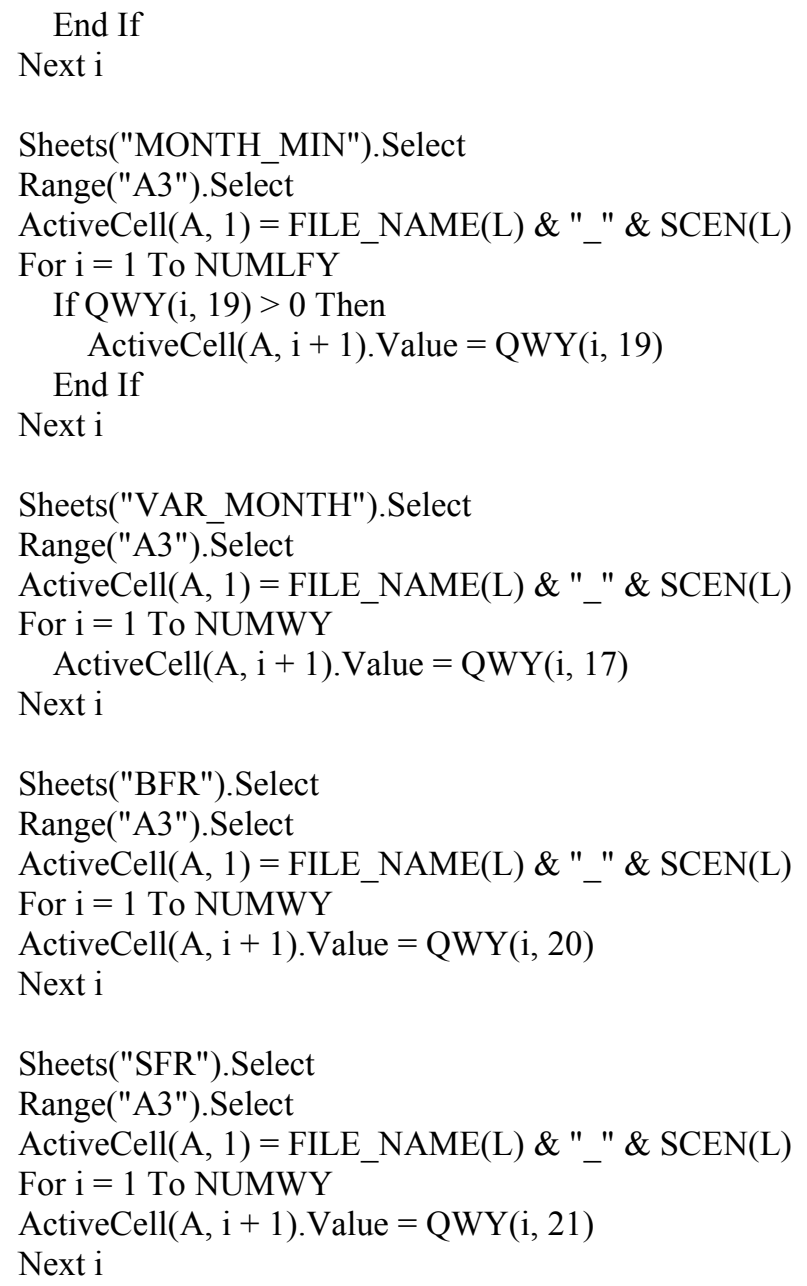

'Write mean flow and 1st percentile of percent daily change to SUMMARY sheet

Sheets("SUMMARY").Select

Range("A3").Select

ActiveCell $(\mathrm{A}, 1)=$ FILE_NAME(L) \& " " \& SCEN(L)

ActiveCell(A, 2) $=$ NUMWY

ActiveCell $(\mathrm{A}, 3)=\mathrm{QMEAN}$

ActiveCell $(\mathrm{A}, 4)=\mathrm{QEX}(10)$

ActiveCell $(\mathrm{A}, 5)=\mathrm{QEX}(100)$

ActiveCell $(\mathrm{A}, 6)=\mathrm{QEX}(250)$

ActiveCell $(\mathrm{A}, 7)=\operatorname{QEX}(500)$

ActiveCell(A, 8) $=\operatorname{QEX}(750)$

ActiveCell(A, 9) $=$ QEX $(900)$

ActiveCell $(\mathrm{A}, 10)=\operatorname{QEX}(990)$

ActiveCell $(\mathrm{A}, 11)=$ PDC50

ActiveCell $(\mathrm{A}, 12)=\mathrm{CVQ}$

ActiveCell $(\mathrm{A}, 13)=\mathrm{CVLOGQ}$

ActiveCell $(\mathrm{A}, 14)=\mathrm{CVLOGQMAX}$

Range(ActiveCell $(0,15)$, ActiveCell( $(0,40))$.Copy

Range(ActiveCell(A, 15), ActiveCell(A, 40)).Select

ActiveSheet.Paste

Range("A3").Select

'Write monthly Qmean to sheet "MONTHLY_QMEAN" 
1 If WRITE RESULTS $=1$ Then

Sheets("MONTHLY QMEAN").Select

Range("A3").Select

ActiveCell $(\mathrm{A}, 1)=$ FILE_NAME(L) \& " _ \& SCEN(L)

For $\mathrm{i}=1$ To $\mathrm{m}$

ActiveCell $(\mathrm{A}, \mathrm{i}+1)=\mathrm{QMONTH}(\mathrm{i}, 3)$

Next i

'Write monthly flow stats to "MONTHQ"

Sheets("MONTHQ").Select

Range("A3").Select

ActiveCell $(\mathrm{A}, 1)=$ FILE_NAME(L) \& " _ \& SCEN(L)

For $\mathrm{i}=1$ To 12

If $i>9$ Then

$\mathrm{j}=\mathrm{i}-9$

Else

$\mathrm{j}=\mathrm{i}+3$

End If

ActiveCell(A, j + 1) = MONTHQSUM(i) / NUMWY

$\operatorname{ActiveCell}(\mathrm{A}, \mathrm{j}+14)=\mathrm{CVMONTHQ}(\mathrm{i})$

ActiveCell $(A, j+27)=\operatorname{MEDMONTHQ}(i)$

Next i

'Write monthly flow stats to "MONTH_EVENTS"

Sheets("MONTH_EVENTS").Select

Range("A3").Select

ActiveCell $(\mathrm{A}, 1)=$ FILE_NAME(L) \& " $" ~ \& \operatorname{SCEN}(\mathrm{L})$

For $\mathrm{i}=1$ To 12

If $\mathrm{i}>9$ Then

$\mathrm{j}=\mathrm{i}-9$

Else

$\mathrm{j}=\mathrm{i}+3$

End If

$\operatorname{ActiveCell}(\mathrm{A}, \mathrm{j}+1)=\operatorname{MEDMONTHHIGHDUR}(\mathrm{i})$

ActiveCell $(\mathrm{A}, \mathrm{j}+14)=$ YEARSHIGHFLOWINMONTH(i) / NUMWY

ActiveCell $(\mathrm{A}, \mathrm{j}+27)=\operatorname{MEDMONTHLOWDUR}(\mathrm{i})$

ActiveCell $(A, j+40)=$ YEARSLOWFLOWINMONTH(i) / NUMWY

Next i

'Write bioperiod flow stats

Sheets("BIOPERIODS").Select

Range("A3").Select

ActiveCell $(\mathrm{A}, 1)=$ FILE_NAME(L) \& " " \& SCEN(L)

For $\mathrm{i}=1$ To NUM_BPS

$\operatorname{ActiveCell}(\mathrm{A}, \mathrm{i} \overline{+} \mathbf{1})=$ PRIOR_APPRO$(\mathrm{i})$

ActiveCell $(A, i+14)=$ EFLOW_STD $(i)$

$\operatorname{ActiveCell}(\mathrm{A}, \mathrm{i}+28)=$ ADD_ALLLOCATION(i)

Next i

'Write statistics for flow 100 days prior to sampling

If DYFLOW100 > 0 Then

Sheets("100_DAY_STATS").Select

Range("A3").Select

ActiveCell $(\mathrm{A}, 1)=$ FILE_NAME(L) \& " " \& SCEN(L)

ActiveCell $(\mathrm{A}, 2)=\mathrm{QMEAN} 100 / 100$

$\operatorname{ActiveCell}(\mathrm{A}, 3)=\mathrm{QMAX} 100$ 
ActiveCell $(\mathrm{A}, 4)=\mathrm{QMIN} 100$

ActiveCell(A, 5) $=$ DURHIGH100

ActiveCell(A, 6) $=$ DURLOW100

ActiveCell(A, 7) $=$ PDC100 / DYFLOW100

End If

'INSERT ADDITIONAL COMMANDS FOR WRITING OUTPUT USING THE FOLLOWING LINES AS A TEMPLATE Sheets(NAME OF SHEET IN DOUBLE QUOTES).Select

Range("A3").Select

ActiveCell(A, 1) = FILE_NAME(1) \& " " \& SCEN(1)

ActiveCell $(\mathrm{A}, 2)=$ NAME OF VARIABLE

'End of writing output to worksheets except daily flows

' $\quad$ End If

'Write minimum, median, mean, and maximum daily flow for each month in the period of record

'to file for each scenario ending with "MONTH.CSV"

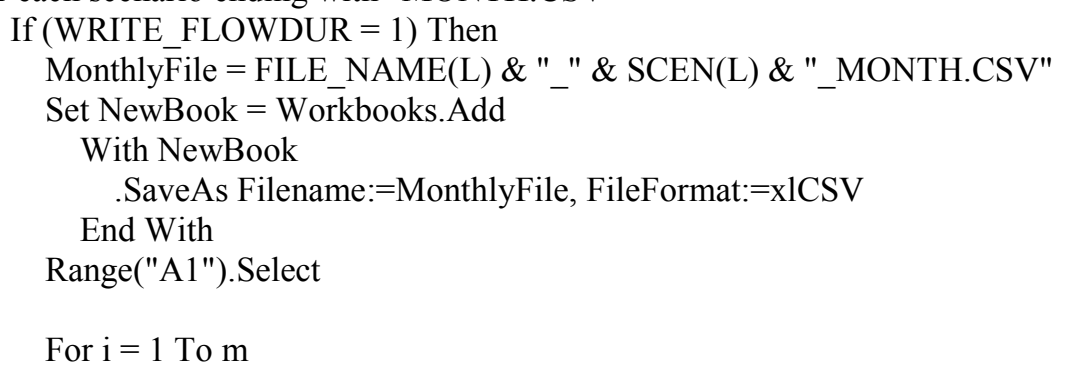

'Monthly flow stats: year, month, minimum, median, mean, maximum, duration of high flows, and duration of low flows

ActiveCell(i, 1) $=$ QMONTH $(\mathrm{i}, 1)$

ActiveCell(i, 2) $=$ QMONTH $(\mathrm{i}, 2)$

ActiveCell(i, 3) $=$ QMONTH $(\mathrm{i}, 4)$

ActiveCell( $(\mathrm{i}, 4)=\mathrm{QMONTH}(\mathrm{i}, 8)$

ActiveCell(i, 5) $=$ QMONTH $(\mathrm{i}, 3)$

ActiveCell( $(\mathrm{i}, 6)=\mathrm{QMONTH}(\mathrm{i}, 5)$

ActiveCell( $(\mathrm{i}, 7)=\mathrm{QMONTH}(\mathrm{i}, 6)$

ActiveCell(i, 8) $=$ QMONTH $(\mathrm{i}, 7)$

Next i

ActiveWorkbook.Close SaveChanges:=True

'Write summary data from flow duration to "FLOW_DUR" file

FlowDurFile = FILE_NAME(L) \& " " \& SCEN(L) \& "_FLOWDUR.CSV"

Set NewBook $=$ Workbooks.Add

With NewBook

.SaveAs Filename $:=$ FlowDurFile, FileFormat: $=x 1 C S V$

End With

Range("A1").Select

$\mathrm{j}=0$

For $\mathrm{i}=1$ To 1000

$\mathrm{j}=\mathrm{j}+1$

ActiveCell $(\mathrm{j}, 1)=\mathrm{i} / 1000$

ActiveCell( $\mathrm{j}, 2)=\mathrm{QEX}(\mathrm{i})$

Next i

ActiveWorkbook.Close SaveChanges:=True

End If

'WRITE DAILY TIME-SERIES OF STREAMFLOW TO "QDAILY" AND CALCULATE EFLOWS

'Columns for each site are date, streamflow record, flow after appropriation and allocation (EFLOW scenario). 


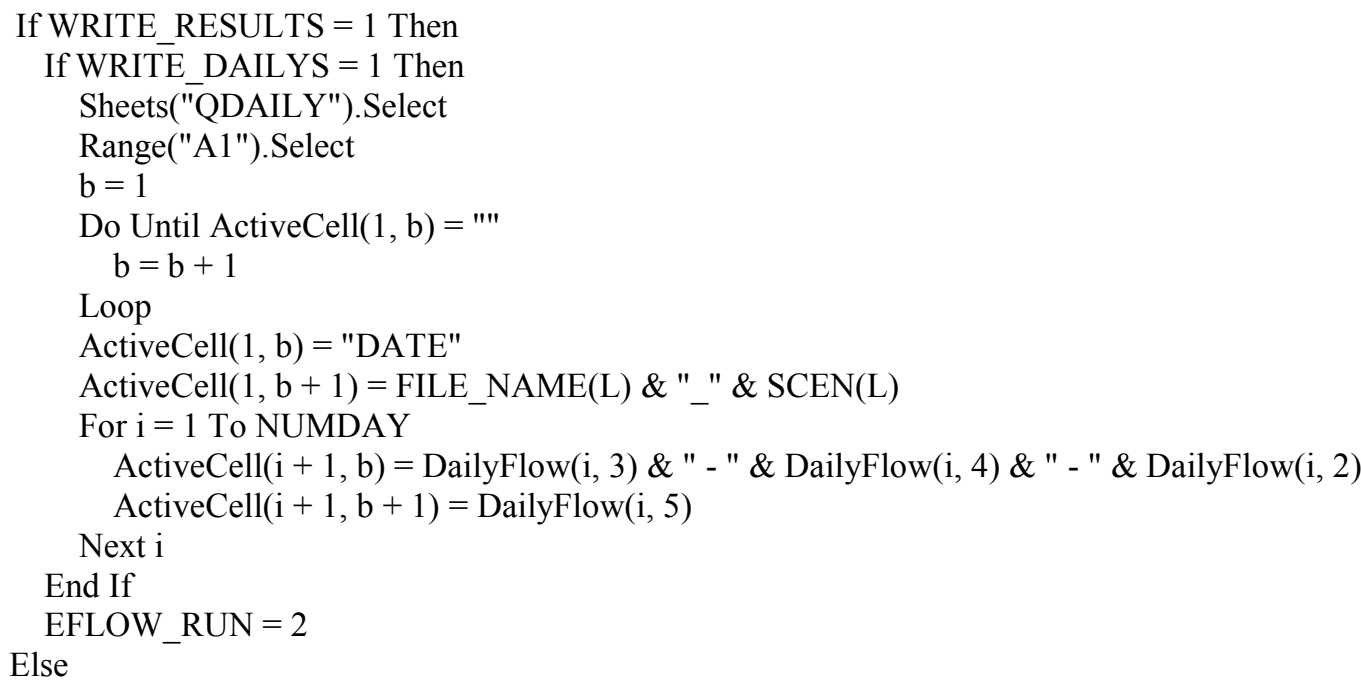

'Determine eflow standards and additional allocations based on statistics for the initial scenario $($ EFLOW_RUN $=0)$ 'Otherwise (EFLOW_RUN=1 or 2), this section in skipped because the standards and allocations have already been calculated.

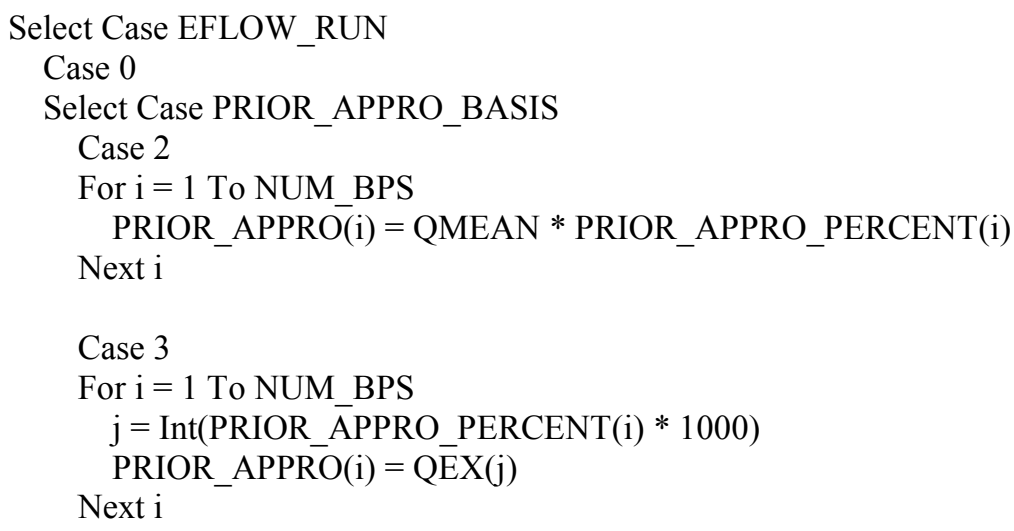

'Case 4 was already calculated

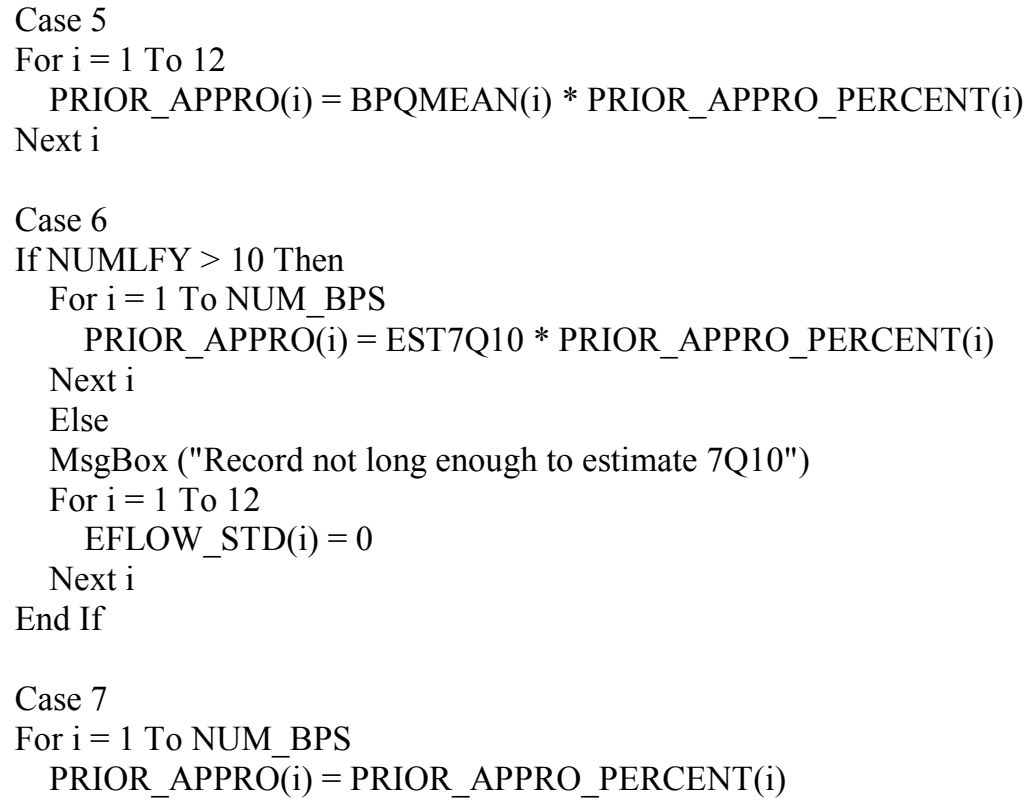


Next i

End Select

'Establish environmental flow standard for each bioperiod (i)

Select Case EFLOW_BASIS

'Case 1 is calculated when the daily flows are written to sheet QDAILY

Case 2

For $\mathrm{i}=1$ To NUM BPS

EFLOW_STD $(\mathrm{i})=$ QMEAN $*$ EFLOW_PERCENT(i)

Next $\mathrm{i}$

Case 3

For $\mathrm{i}=1$ To NUM_BPS

$\mathrm{j}=\operatorname{Int}($ EFLOW_PERCENT(i) $* 1000)$

EFLOW_STD $(\overline{\mathrm{i}})=\mathrm{QEX}(\mathrm{j})$

Next i

'Case 4 was already calculated

Case 5

For $\mathrm{i}=1$ To 12

EFLOW_STD(i) $=$ BPQMEAN $(i) *$ EFLOW_PERCENT(i)

Next i

Case 6

If NUMLFY $>10$ Then

For $\mathrm{i}=1$ To NUM_BPS

EFLOW_STD(i) $=$ EST7Q10 $*$ EFLOW_PERCENT(i)

Next i

Else

MsgBox ("Record not long enough to estimate 7Q10")

For $\mathrm{i}=1$ To 12

EFLOW_STD $(i)=0$

Next i

End If

Case 7

For $\mathrm{i}=1$ To NUM_BPS

EFLOW_STD(i) $=$ EFLOW_PERCENT(i)

Next i

End Select

'Establish maximum ADD_ALLOCATION for each period (i)

Select Case ADD_ALLOCATION_BASIS

'Case 1 is calculated when the time-series is written to QDAILY sheet.

Case 2

For $\mathrm{i}=1$ To NUM_BPS

ADD_ALLOCATION(i) $=$ QMEAN *ADD_ALLOCATION_PERCENT(i)

Next i

Case 3

For $\mathrm{i}=1$ To NUM BPS

$\mathrm{j}=\operatorname{Int}\left(A D D \_A L L O C A T I O N \_P E R C E N T(i) * 1000\right)$

ADD_ALLOCATION $(\mathrm{i})=\overline{\mathrm{QEX}}(\mathrm{j})$

Next i 
'Case 4 was already calculated

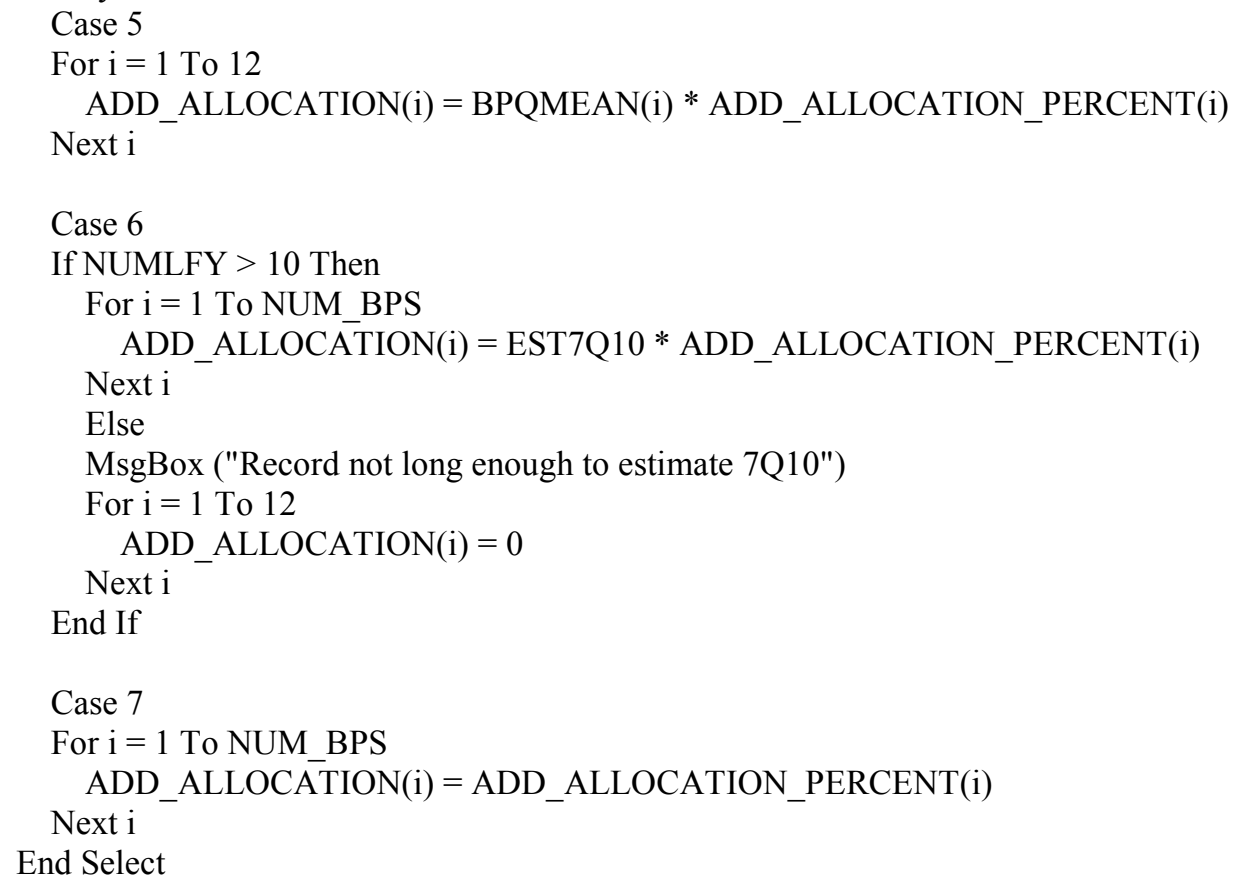

'Daily prior appropriations and eflow standards

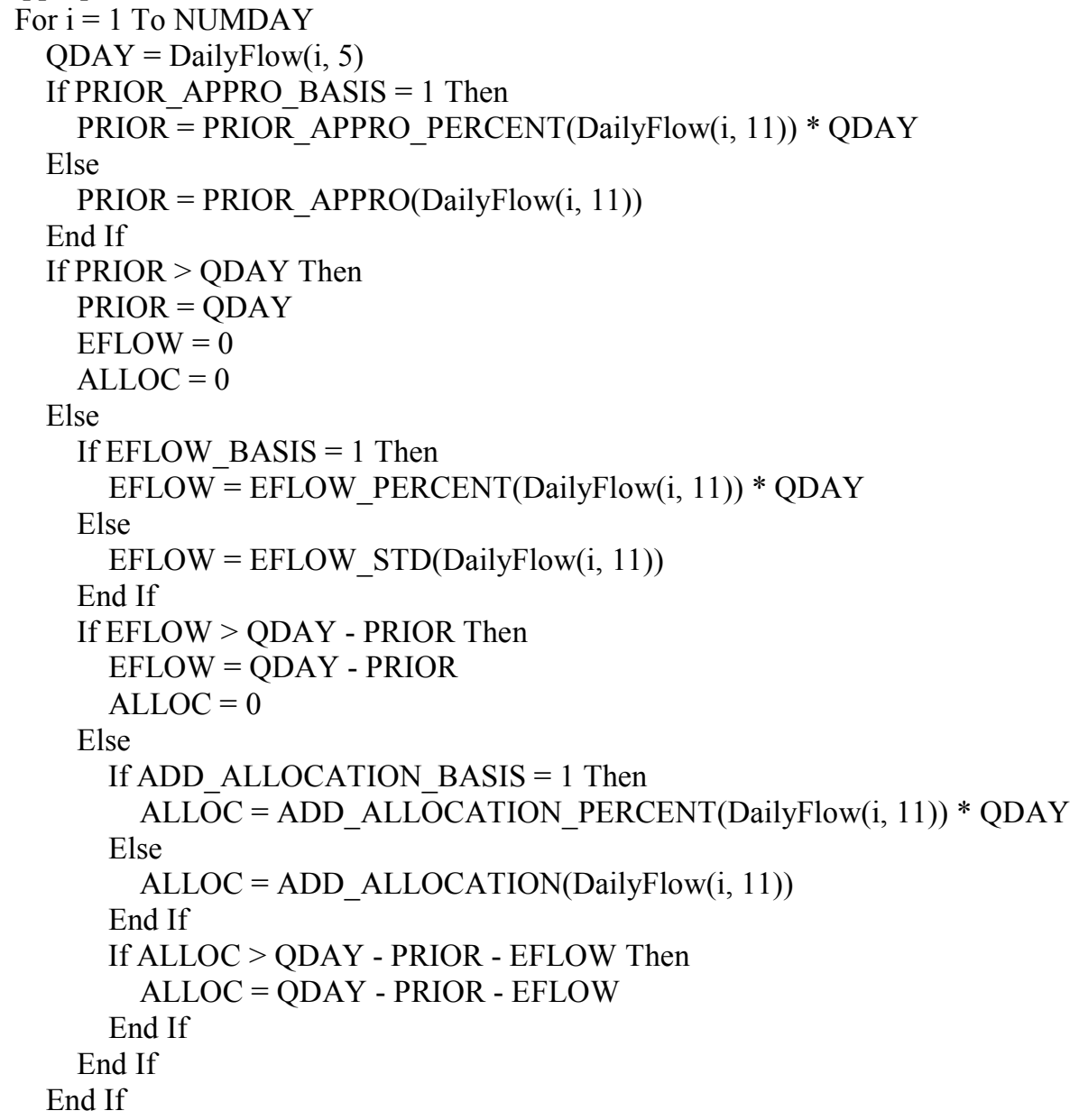


'Time-series of streamflow after prior appropriation and additional allocations for EFLOW_RUN statistics

DailyFlow(i, 5) = QDAY - PRIOR - ALLOC

If DailyFlow(i, 5) $<0$ Then

MsgBox ("whoa")

End If

Next i

'Switches the value of ELFLOW_RUN from 0 to 1

EFLOW_RUN $=1$

'Switches the value of ELFLOW_RUN from 1 to 2

Case 1

EFLOW_RUN $=2$

Case 2

EFLOW_RUN $=2$

End Select

'If eflows, and allocation are not specified, then the program will just loop through the data once and calculate statistics End If

'Loop for EFLOW_RUN $<2$

Loop

'If site doesn't have the minimum number of years, above lines are skipped End If

'RE-INITIALIZE VARIABLES AND ARRAYS FOR EACH SCENARIO

STARTWY $=0$

$\mathrm{ENDWY}=0$

THRESH_HIGH_TYPE $=0$

THRESH_LOW_TYPE $=0$

CALC_EFLOW $=0$

WRITE_FLOWDUR $=0$

WRITE DAILYS $=0$

EFLOW_RUN $=0$

WRITE RESULTS $=0$

$\mathrm{WY}=0$

$\mathrm{YR}=0$

$\mathrm{MN}=0$

$\mathrm{DY}=0$

WY_NEXTDAY $=0$

$\mathrm{LFY}=0$

LEAPYEAR $=0$

NUMDAY $=0$

NUMWY $=0$

NUMLFY $=0$

DYINYEAR $=0$

DYINMONTH $=0$

NEXTLOWFLOWYEAR $=0$

ZERODAY $=0$

NUM_BPS $=0$

PRIOR_APPRO_BASIS $=0$

EFLOW_BASIS $=0$

ADD_ALLLOCATION_BASIS $=0$

PRIOR $=0$

$\mathrm{EFLOW}=0$ 
$\mathrm{ALLOC}=0$

Erase PRIOR_APPRO_PERCENT, PRIOR_APPRO, EFLOW_PERCENT, EFLOW_STD, ADD_ALLOCATION_PERCENT, ADD_ALLOCATION

Erase DailyFlow, TempDailyFlow, QEX, WYDAYS, QWY, QDYWY, QMONTH

Erase QBP, BPQSUM, BPQMEAN, BP_START, DYINBP, MONTHQSUM, CVMONTHQ, MEDMONTHQ, LOGQMAX

Erase MEDMONTHHIGHDUR, MEDMONTHLOWDUR, YEARSLOWFLOWINMONTH, YEARSHIGHFLOWINMONTH

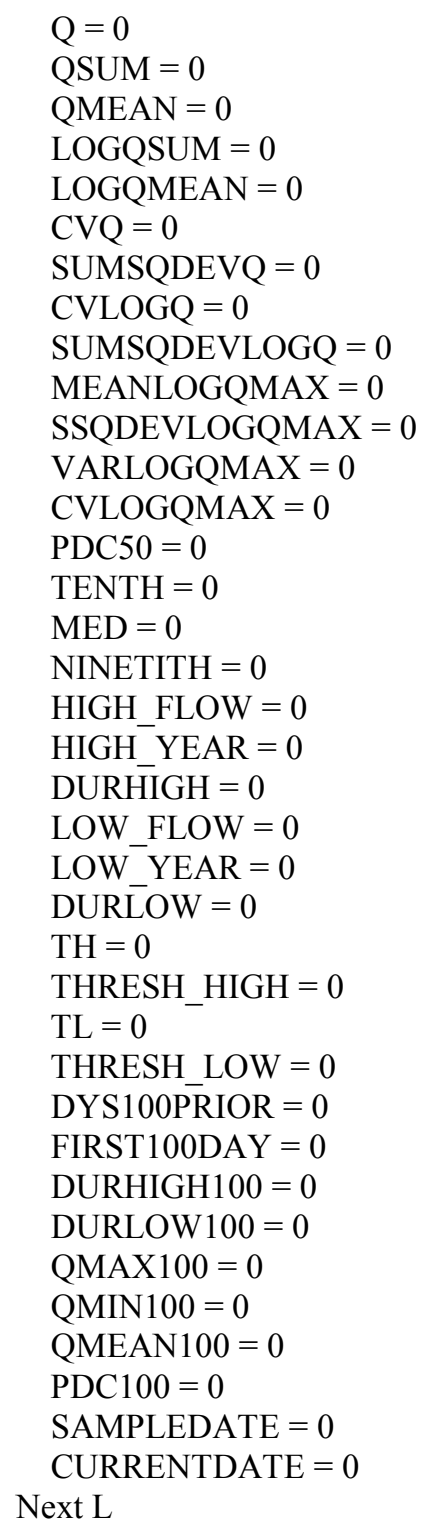




\section{हू}

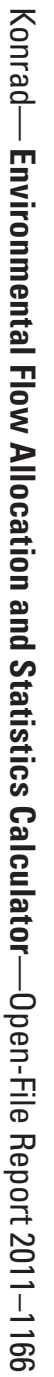

6 Printed on recycled paper 
Publishing support provided by the U.S. Geological Survey

Publishing Network, Tacoma Publishing Service Center

For more information concerning the research in this report, contact the Director, Washington Water Science Center

U.S. Geological Survey

934 Broadway, Suite 300

Tacoma, Washington 98402

http://wa.water.usgs.gov 